\title{
Data Quality Assessment of Maintenance Reporting Procedures
}

\author{
Manik Madhikermi ${ }^{\mathrm{a}}$, Sylvain Kubler ${ }^{\mathrm{b}, *}$, Jérémy Robert ${ }^{\mathrm{b}}$, Andrea Buda ${ }^{\mathrm{a}}$, Kary Främling ${ }^{\mathrm{a}}$ \\ ${ }^{a}$ Aalto University, School of Science \\ P.O. Box 15400, FI-00076 Aalto, Finland \\ ${ }^{b}$ University of Luxembourg, Interdisciplinary Centre for Security, Reliability $\mathcal{G}$ Trust \\ 4 rue Alphonse Weicker L-2721 Luxembourg
}

\begin{abstract}
Today's largest and fastest growing companies' assets are no longer physical, but rather digital (software, algorithms...). This is all the more true in the manufacturing, and particularly in the maintenance sector where quality of enterprise maintenance services are closely linked to the quality of maintenance data reporting procedures. If quality of the reported data is too low, it can results in wrong decision-making and loss of money. Furthermore, various maintenance experts are involved and directly concerned about the quality of enterprises' daily maintenance data reporting (e.g., maintenance planners, plant managers...), each one having specific needs and responsibilities. To address this Multi-Criteria Decision Making (MCDM) problem, and since data quality is hardly considered in existing expert maintenance systems, this paper develops a Maintenance Reporting Quality Assessment (MRQA) dashboard that enables any company stakeholder to easily - and in real-time - assess/rank company branch offices in terms of maintenance reporting quality. From a theoretical standpoint, AHP is used to integrate various data quality dimensions as well as expert preferences. A use case describes how the proposed MRQA dashboard is being used by a Finnish multinational equipment manufacturer to assess and enhance reporting practices in a specific or a group of branch offices.
\end{abstract}

Keywords: Data Quality, Information Quality, Multi-Criteria Decision Making, Analytic Hierarchy Process, Decision Support Systems, Maintenance.

\section{Introduction}

Data and Information quality is one of the most competitive advantages for an organization in today's digital age, for example, with the rapid evolution of Internet of Things, Industry 4.0, Big Data and Cloud Computing (Xu et al., 2010; Chen et al., 2014). Companies are trying hard to find out relevant strategies to make their products (physical or virtual) standout with respect to their competitors. Quality improvement of products, processes and services requires the collection and analysis of data to solve quality-related problems (Li et al., 2015; Köksal et al., 2011). Companies need to provide after-sales services such as maintenance and warranty services to ensure that the delivered product is reliable and in full accordance with the customer requirements. Nonetheless, providing such services inevitably generate costs for businesses (Fang \& Huang, 2008). As indicated by Mobley (2002), one third of all maintenance costs is wasted as the

\footnotetext{
${ }^{*}$ Corresponding author

Email addresses: manik.madhikermi@aalto.fi (Manik Madhikermi), sylvain.kubler@uni.lu (Sylvain Kubler), jeremy.robert@uni.lu (Jérémy Robert), andrea.buda@aalto.fi (Andrea Buda), kary.framling@aalto.fi (Kary Främling)

result of unnecessary or improper maintenance practices. More recent studies have confirmed that maintenance is a major cost issue, with a ratio between maintenance costs and added-value higher than $25 \%$ in some sectors (Sophie et al., 2014). In fact, data quality practices - including maintenance reports - have a considerable impact on maintenance tasks, risks and business performance since poor data quality results in losses across a number of fronts (Arputhamary \& Arockiam., 2015), and reciprocally, high data quality fosters enhanced business activities and decisionmaking.

A successful maintenance program often relies on a detailed planning and intelligent decision-making support systems. This is all the more true given that planning maintenance involves managing a set of complex tasks and resources to guarantee the maximum possible operational availability of equipment (Palma, 2010). Various stakeholders with different responsibilities are involved in this management, such as (i) Maintenance planners who are responsible for scheduling planned maintenance activities; (ii) Plant managers who are responsible for cost reporting and savings; (iii) Maintenance managers who are responsible for the execution of planned/unplanned maintenance activities, and so on. All these experts have 
a common goal: reducing maintenance downtime to increase productivity. In this respect, they usually make use of maintenance reports as decision support tools, which contain useful record information such as technical maintenance logs, asset location, description of defect location codes, scheduled maintenance date, etc. It is thus of importance to develop and implement strategies for enhanced reporting practices, data quality control and management (Jones-Farmer et al., 2014). Nonetheless, requirements related to the data and associated quality attributes are tightly coupled with the stakeholder's needs and responsibilities. For example, maintenance managers pay more attention to technical log records for their daily decisionmaking, whereas plant managers rather use defect and asset location-related information to manage their inventory. All this provides irrefutable evidence of the complexity of developing a flexible, intelligent and integrated decision-making support system for data quality assessment and maintenance management; it implies to take into consideration various stakeholder roles, needs, quality dimensions, and other technical and organizational aspects (Vujanovićet al., 2012; Shafiee , 2015). Given the Multi-Criteria Decision Making (MCDM) nature of the problem, this paper investigates and develops a Maintenance Reporting Quality Assessment (MRQA) tool, whose underlying framework relies on AHP. The primary goal of this tool is to help companies to dynamically assess quality of daily maintenance data reporting activities, while taking into account specific needs or role of the end-user (i.e., a company stakeholder).

The summary of the paper is as follows: Section 2 conducts a thorough literature review of both (i) existing expert maintenance systems making use of MCDM techniques, and (ii) existing data quality frameworks, against which our research is motivated. Section 3 provides insight into the research methodology underlying the MRQA framework/tool development. Section 4 thoroughly details the MRQA framework and underlying mathematical theory. Section 5 describes a use case that shows how the proposed MRQA decision-making support dashboard is being used by a Finnish multinational Original Equipment Manufacturer (OEM) company to assess and rank company branch offices in terms of maintenance reporting quality. Conclusions, implications, limitations and future research are discussed in Section 6.

\section{Data quality in expert maintenance systems}

To understand how crucial and complex it is to properly address data quality in maintenance settings, section 2.1 discusses the key maintenance business levels, along with previous research works that have used MCDM techniques to address challenges at each of these levels. Section 2.2 discusses existing frameworks for data quality analysis and management in maintenance processes.

\subsection{Expert maintenance systems}

Maintenance is a complex process that is usually triggered by an equipment failure or planned repair. This process requires planning, scheduling, controlling as well as deploying maintenance resources to perform the necessary maintenance actions (Duffuaa et al., 2001). Adopting an efficient approach to organize maintenance management (MM) activities is a prerequisite to its success. Several MM frameworks have been developed and applied for this purpose, one of the earliest being put forward by Pintelon \& Gelders (1992) who pointed out three important business levels in the decision-making process, including the (i) Operational level: decision regarding marketing and finance; ii) Planning $\mathcal{E}$ control level: decisions regarding resource and scheduling management, and performance reporting; iii) Managerial level: decisions regarding how to optimize actions and policies to be performed on-site. Later on, Levrat et al. (2008) proposed a similar three business level-based MM framework, namely:

- Strategic level: strategic axis are expressed in quantitative and qualitative terms, and organizational maintenance strategies are defined such as corrective and preventive maintenance, riskbased or condition-based maintenance, etc.;

- Tactical level: maintenance actions such as scheduling and resource planning are planned;

- Operational Level: actual work is carried out in addition to access performance and future equipment conditions.

Making decisions at each of these three levels implies dealing with multiple, conflicting, and incommensurate criteria and/or objectives, as well as human judgments. Research on human judgements and decision making shows that the human brain is able to consider only a limited amount of information at any one time (Simpson, 1996), which makes it unreliable to take decisions when facing complex problems. MCDM techniques, such as AHP, TOPSIS, ELECTRE, PROMETHEE, Fuzzy MCDM, etc., have been proven to be of great value in supporting decisionmakers at each MM level, as summarized in Table 1.

At the "Strategic level", MCDM techniques are considered for various purposes, including (i) maintenance policy selection, (ii) tool/contractor selection, and (iii) cost estimation. Table 1 provides an "at a glance" overview of scientific papers that have made use of MCDM techniques for each of these purposes. Bevilacqua and Braglia (2000); Wang et al. (2007); 
Table 1: MCDM Techniques Applied in Maintenance Industry

\begin{tabular}{|c|c|c|c|c|c|c|c|c|c|}
\hline 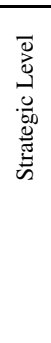 & $\begin{array}{l}\text { Maintenance Policy Se- } \\
\text { lection }\end{array}$ & $\begin{array}{l}\text { AHP } \\
\text { (Bertolini } \\
\text { Bevilacqua, and } \\
\text { Bevilacqua and } \\
\text { Braglia, 2000; } \\
\text { Goossens et al., } \\
\text { 2015; Labib et al., } \\
\text { 1998; Pramod et } \\
\text { al., 2007; Shyjith et } \\
\text { al., 2008; Tan et al., } \\
\text { 2011; Zaim et al., } \\
\text { 2012) }\end{array}$ & $\begin{array}{l}\text { FAHP } \\
\text { (Azizi et al., 2014; } \\
\text { Ilangkumaran \& Ku- } \\
\text { manan, 2009; Hos- } \\
\text { seini et al., 2015; } \\
\text { Ferdousmakan et al., } \\
\text { 2014; Wang et al., } \\
\text { 2007; Fouladgar et } \\
\text { al., 2012) }\end{array}$ & $\begin{array}{l}\text { ANP } \\
\text { (Kumar \& Maiti, } \\
\text { 2012; Shahin et al., } \\
\text { 2012; Pourjavad et } \\
\text { al., 2013; Zaim et al., } \\
\text { 2012) }\end{array}$ & $\begin{array}{l}\text { DEA } \\
\text { Azadeh et al. (2014); } \\
\text { Sheikhalishahi } \\
\text { (2014) }\end{array}$ & $\begin{array}{l}\text { VIKOR } \\
\text { (Ilangkumaran \& } \\
\text { Kumanan, 2012; } \\
\text { Ahmadi et al., 2010) }\end{array}$ & $\begin{array}{l}\text { ELECTRE } \\
\text { (Zhangqiong \& } \\
\text { Guozheng, 1999; Li } \\
\text { et al., 2007) }\end{array}$ & $\begin{array}{l}\text { PROMOTHEE } \\
\text { (Emovon et al. } \\
2015 ; \text { de et al., } \\
2015 \text { c; Monte et al., } \\
2015 \text { ) }\end{array}$ & MAUT \\
\hline & $\begin{array}{l}\text { Tools and companies Se- } \\
\text { lection }\end{array}$ & $\begin{array}{l}\text { (Bertolini et al., } \\
\text { 2004; Garcí- } \\
\text { Cascales et al., 2009; } \\
\text { Ha et al., 2008; } \\
\text { Triantaphyllou et al., } \\
\text { 1997) } \\
\text { (Chou, 2009) }\end{array}$ & (Durán, 2011) & & (Ha et al., 2008) & & $\begin{array}{l}\text { (dGonçalves et al., } \\
\text { 2014; Gomez et al., } \\
\text { 2011) }\end{array}$ & & $\begin{array}{l}\text { (Kuo et al., 2012; de } \\
\text { et al., 2015a) }\end{array}$ \\
\hline & $\begin{array}{l}\text { Maintenance prioritiza- } \\
\text { tion }\end{array}$ & $\begin{array}{l}\text { (Farhan \& Fwa, } \\
\text { 2009; Moazami et } \\
\text { al., 2011; Taghipour } \\
\text { et al., 2011) }\end{array}$ & (Ouma et al., 2015) & & $\begin{array}{l}\text { (Wakchaure \& Jha, } \\
\text { 2011) }\end{array}$ & & $\begin{array}{l}\text { (Liu et al., 2012; } \\
\text { Cafiso et al., 2002; } \\
\text { Hankach et al., 2011; } \\
\text { Trojan \& Morais, } \\
\text { 2012b) }\end{array}$ & & 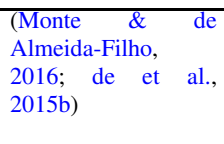 \\
\hline & Maintenance Scheduling & $\begin{array}{l}\text { (Coulter et al., 2006; } \\
\text { Eslami et al., 2014) }\end{array}$ & & & (Van et al., 2013) & & (Certa et al., 2013) & $\begin{array}{l}\text { (Cavalcante et al., } \\
\text { 2010; Almeida et al., } \\
\text { 2013) }\end{array}$ & $\begin{array}{l}\text { (Garmabaki et al., } \\
\text { 2016; de Almeida., } \\
\text { 2001; Liu \& Fran- } \\
\text { gopol, 2006) } \\
\text { (Almeida, A. T., } \\
\text { 2012) }\end{array}$ \\
\hline \multirow[t]{2}{*}{ 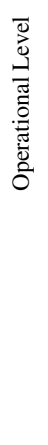 } & $\begin{array}{l}\text { Critical Component Iden- } \\
\text { tification } \\
\text { Measuring/Assessment } \\
\text { Efficiency }\end{array}$ & (Wang et al., 2010) & $\begin{array}{l}\text { (Dehghania et al., } \\
\text { 2012) }\end{array}$ & $\begin{array}{l}\text { (Muchiri et al., } \\
\text { 2011; Vujanovićet } \\
\text { al., 2012; Van \& } \\
\text { Pintelon, 2014) }\end{array}$ & $\begin{array}{l}\text { Sun (2004); Peck } \\
\text { et al. (1998); Ozbek } \\
\text { et al. (2010a,b); } \\
\text { Hjalmarsson et al. } \\
\text { (1996); Liu \& Yu } \\
\text { (2004); Rouse et al. } \\
\text { (2002); Fallah-Fini } \\
\text { et al. (2015); Jeon et } \\
\text { al. (2011); Roll et al. } \\
\text { (1989); Charnes et } \\
\text { al. (1984) }\end{array}$ & & & $\begin{array}{l}\text { (Cavalcante et al. } \\
2007,2010) \\
\text { (de un Caso, 2008) }\end{array}$ & (e Costa et al., 2012) \\
\hline & $\begin{array}{l}\text { Maintenance Action Se- } \\
\text { lection }\end{array}$ & & $\begin{array}{l}\text { (Kumar \& Maiti, } \\
\text { 2012) }\end{array}$ & & & & $\begin{array}{l}\text { (Alarcón et al., 2007; } \\
\text { Thor et al., 2013) }\end{array}$ & & \\
\hline
\end{tabular}


Tan et al. (2011); Fouladgar et al. (2012) developed MCDM-based maintenance policy selection frameworks taking into account maintenance cost, addedvalue and safety dimensions. Shahin et al. (2012) rather focused on the selection of appropriate (optimum) maintenance strategies, paying special attention to reliability, availability and maintainability criteria and potential interdependencies (via ANP). Gomez et al. (2011); Durán (2011) developed a similar approach, considering the same criteria, but rather applying ELECTRE II and FAHP respectively. Selecting appropriate tools and/or contractors for outsourcing activities plays also an important role at the strategic level, as it affects the whole maintenance management process. In this respect, Bertolini et al. (2004) developed an AHP-based outsourcing service selection model considering maintenance-related criteria. Maintenance budgeting and cost estimation are other important strategic decisions that need to be properly managed. To this end, Chou (2009) and Chen et al. (2005) develop two distinct utility-based assessment approaches, respectively relying on AHP and ELECTRE II, which enable decision-makers to estimate based on historical data of similar projects - pavement and pipeline maintenance costs.

Looking at the "Tactical level" now, MCDM techniques are mainly applied for maintenance work planning purposes, which includes (i) task prioritization, (ii) task scheduling, and (iii) resource planning. Table 1 reports some scientific papers that have made use of MCDM techniques for each of these purposes. Cafiso et al. (2002); Farhan \& Fwa (2009); Moazami et al. (2011); Ouma et al. (2015) and Babashamsi et al. (2016) have all studied prioritization of road maintenance with the objective to reduce the overall cost (criteria considered in this studies being traffic volume, road safety, pavement width...). Other studies such as (Trojan \& Morais, 2012a,b; Monte \& de AlmeidaFilho, 2016) developed MCDM-based frameworks for maintenance prioritization in the context of water supply networks, looking at strategies for reducing costs and water losses. Taghipour et al. (2011) developed a framework in the context of healthcare maintenance management for medical equipment prioritization, considering mission criticality, age, risk, recall and hazard alerts as main prioritization criteria. Resource planning is also a very critical aspect to be tackled at the tactical level, as resources can be either human or non-human in nature. For example, Van et al. (2013) develop a three-stage approach of personnel rostering (i.e., human scheduling) for aircraft maintenance, whereas de Almeida. (2001) are seeking to optimize spare-provisioning (i.e., non-human resource allocation).

Finally, at the "Operational level", MCDM techniques are often applied for (i) task efficiency assessment, (ii) Critical component identification, and (iii)
Maintenance action selection. Table 1 shows that most of the papers implement a data envelopment analysis (DEA) for task efficiency assessment, which is a well-known tool for benchmarking in operations management. The identification of critical components is also very important to addressed to offer enhanced predictive maintenance services (Cavalcante et al. , 2010; Dehghania et al., 2012). Along with critical component identification comes the challenge of making the right decisions and actions on the field to avoid causing any disruption, delay or monetary loss. A few studies have been using MCDM techniques to select the best maintenance action(s) on-site, such as Nyström \& Söderholm (2010) who are seeking to improve railway track maintenance practices, or still Alarcón et al. (2007) who apply ELECTRE for minimizing telecommunication network disruption during maintenance activities.

Given the significant number of papers discussed above and classified in Table 1 (40 papers at the Strategic level, 19 at the Tactical level, and 20 at the Operational level), we feel it is appropriate to analyze and identify criteria that are the most commonly used at each MM level, which will therefore help us to state whether or not existing studies takes into account data quality-related criteria. The outcome of our analysis shows that the three most commonly used criteria at each MM level are (see Appendix B for a complete overview of the analysis outcome and criteria lists):

- Strategic level: (i) Cost (22.7\%), (ii) Resource Availability \& Utilization (10.1\%), Added value $(7.6 \%)$;

- Tactical level: Cost (21.9\%), Environmental/Operational Conditions (8.7\%) and Safety (9.4\%);

- Operational Level: Cost (25.8\%), Resource Availability \& Utilization (19.4\%) and Added Value $(4.8 \%)$.

These results clearly show that data quality is hardly considered in the reviewed papers, whereas it can have a major impact on expert decisions, as previously discussed. The only paper that integrates a data quality criterion is (Van \& Pintelon, 2014), where the authors measure the "accuracy" of maintenance report records. Given the fact that existing expert maintenance systems fail, or have no specific interest, to take into account various data quality dimensions, as well as in providing experts with the possibility to specify - in real-time - their own preferences regarding each of these dimensions, our research aims to fulfill this gap by adapting existing data quality frameworks to the maintenance sector (the next section discussing such frameworks). From the MM's viewpoint, our research primarily addresses the "Tactical" and "Operational" levels with the objective to assess quality of enterprises' daily maintenance reporting activities. 


\subsection{Data quality frameworks}

Although first data or information quality frameworks were introduced back in the 90' (Krogstie et al., 1995; Wang \& Strong, 1996; Jarke \& Vassiliou, 1997), research efforts has recently gained momentum in an increasingly number of sectors due to the digitalization of almost every industry, e.g. in the context of $i$ ) smart cities for open data portal quality assessment, e.g. in (Umbrich et al., 2015) whose metadata items are assessed in terms of quality; ii) product lifecycle management, e.g. in (Wellsandt et al., 2015) where authors separate 'fitting' from 'unfitting' information from a manufacturing/design decision process perspective; iii) query processing, e.g. in (Sampaio et al., 2015) for incorporating data quality profiling dimensions in the processing of queries involving quality-aware query language extensions; or more recently (iv) Google's Analytics Advocate shared his own framework "TITE" (time, interactions, trends, and events) to help marketers gain context and get actionable insights from their data (Waisberg, 2015).

Although some data quality frameworks are generic enough to be applied in different contexts and sectors (Krogstie et al., 1995; Kahn et al., 2002; Maurino \& Batini, 2009), they often need to be tuned/adapted to each application case. It is, nonetheless, difficult to state in what respects one framework is better than another since data quality is commonly thought of as a multi-dimensional concept with varying attributed characteristics, which depend on the author's philosophical viewpoint, past experience, application domains, and so forth (Ofner et al., 2013). In our research, we decided to consider the framework introduced by Krogstie et al. (1995) which, even if it dates back to 1995 , provides a very detailed and complete overview of data quality concepts and relationships. Section 3 provides greater detail on the Krogstie's framework, and to what extent it is instanciated to cope with maintenance reporting procedures.

\section{Research Methodology: Data quality frame- work instantiation to MRQA purposes}

The research methodology used in this study for determining what data quality dimensions must be integrated to our model (in light of the MRQA problem) is presented in this section. To this end, section 3.1 presents the high-level concepts and relationships covered by the Krogstie's framework, while section 3.2 describes both what concepts/relationships from that framework are relevant to our problem and how they are integrated based on AHP.

\subsection{Krogstie framework concepts and definitions}

Concepts and relationships underlying the Krogstie's data quality framework are depicted in Figure 1 and described hereinafter:

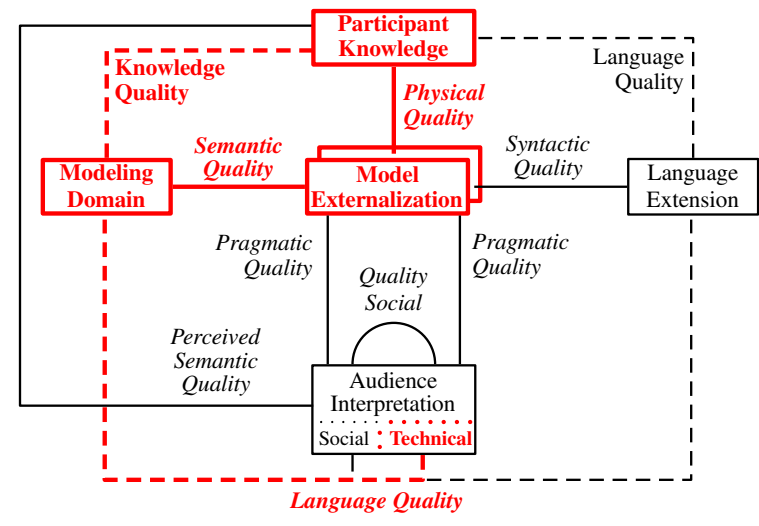

Figure 1: Krogstie's data quality framework

- Physical Quality: about externalizability (i.e., the knowledge of some social actors has been externalized by the use of a conceptual modeling language) and internalizability (i.e., the externalized model is persistent and available, thus enabling participants to make sense of it);

- Syntactic Quality: correspondence between the model and the language extension of the language in which the model is written;

- Semantic Quality: correspondence between the model and domain, where domain is considered as the ideal knowledge about the situation to be modeled. Krogstie's framework contains two semantic goals: Validity and Completeness;

- Perceived Semantic Quality: correspondence between the actor interpretation of a model and his/her current knowledge of the domain. In line with the semantic quality, two goals are defined by the authors: Perceived Validity and Perceived Completeness;

- Pragmatic Quality: correspondence between the model and the "Audience Interpretation" of it;

- Social Quality: about people "agreement";

- Knowledge Quality: from a pure standpoint of social construction, it is difficult to talk about the quality of explicit knowledge. On the other hand, within certain areas such as mathematics, what is regarded as 'true' is comparatively stable, and it is inter-subjectively agreed that certain people have more valid knowledge of an area than others. The 'quality' of the participant knowledge can thus be expressed by the relationship between the audience knowledge and domain;

- Language Quality: appears as means for model quality in the framework. The authors have regrouped factors from earlier discussions on lan- 
Table 2: Criteria and its sub-criteria description related to the data quality dimensions

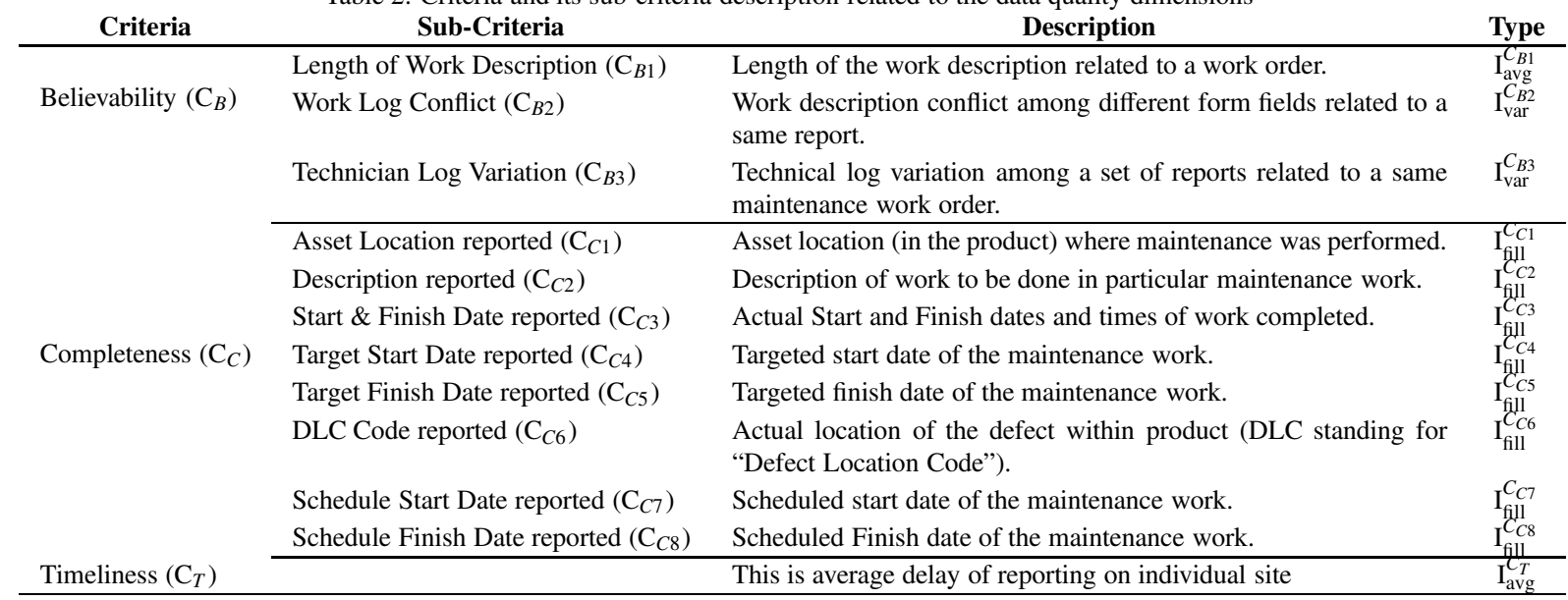

guage quality as follows: $i$ ) Domain appropriateness; ii) Participant Knowledge Appropriateness; iii) Technical actor interpretation enhancement.

\subsection{MCDM-based Krogstie framework instanciation}

Given the above definitions, and based on the Finnish OEM company's requirements, three key concepts/relationships and a working assumption form the foundation of our framework. First, we assume that the Physical Quality ( $c f$. Figure 1), and particularly the externalized model, is $100 \%$ persistent and available, thus enabling participants to make sense of it. A potential study assessing how persistent their implementations are compared with the initial expert statements/knowledge will be achieved in future work. The OEM company then expressed requirements regarding three of the Krogstie's framework concepts/relationships, as highlighted in red/bold in Figure 1, namely:

1. Semantic Quality: the OEM company wants to know to which extent the service data reported by each operator (on each site) can be trusted, or more exactly can be considered as "true", "real" and "credible", in order to carry out the planning activities. This is referred to as the "Believability" criterion $\left(\mathrm{C}_{B}\right)$, whose various facets of $\mathrm{C}_{B}$ are formalized in the form of sub-criteria, i.e. as Believability quality indicators denoted by $\left\{\mathrm{C}_{B 1} . . \mathrm{C}_{B 3}\right\}$ (see Table 2 for more information);

2. Language Quality: the OEM company wants to know to which extent the service data reported by each operator is complete, or is of sufficient depth and breadth for the task at hand. To put it another way, this criterion, referred to as Completeness $\left(C_{C}\right)$, reflects the level of details reported by each operator with regard to each report/form field that needs to be entered (in accordance with the company's business logic).
Similarly to $\mathrm{C}_{B}$, several Completeness quality indicators are defined, respectively denoted by $\left\{\mathrm{C}_{C 1} \ldots \mathrm{C}_{C 8}\right\}$ (see Table 2);

3. Knowledge Quality: the OEM company wants to know to which extent the service data reported by each operator is sufficiently "up to date", which is depending on the time difference between the maintenance work achievement and the task reporting. This criterion, referred to as Timeliness $\mathrm{C}_{T}$, is based on the assumption that the longer the time spent to submit the report, the lesser the quality of the reporting (operator are likely to forget details over time). As emphasized in Table 2, no sub-criterion is defined for this dimension.

To ease the understanding of those data quality dimensions and sub-dimensions, an illustration of the overall maintenance reporting quality assessment is presented in Figure 2. First, maintenance operators carry out maintenance work orders/tasks on each OEM site (denoted by Site 1 ... Site $z$ ), thus generating multiple reports. Figure 2 presents a simplified view of (i) the report's content, and (ii) the comparison process based on the criteria introduced in Table 2. We emphasize, using "smileys", how and why a report's content (or form field content) can positively or negatively impact on the maintenance reporting quality.

In light of the MCDM problem - integration of various quality dimensions, expert preferences, report contents... - AHP has been chosen to help organizing critical aspects of the problem in a manner similar to that used by the human brain in structuring the knowledge (Saaty, 1980). As highlighted in our literature review ( $c f$. section 2), there are a number of MCDM techniques such as AHP/ANP, TOPSIS, ELECTRE, PROMETHEE, MAUT, and much more (e.g., hybrid MCDM combining these techniques together or even with other theories such as fuzzy logic) (Behzadian et al., 2012; Mardani et al., 2015). There 

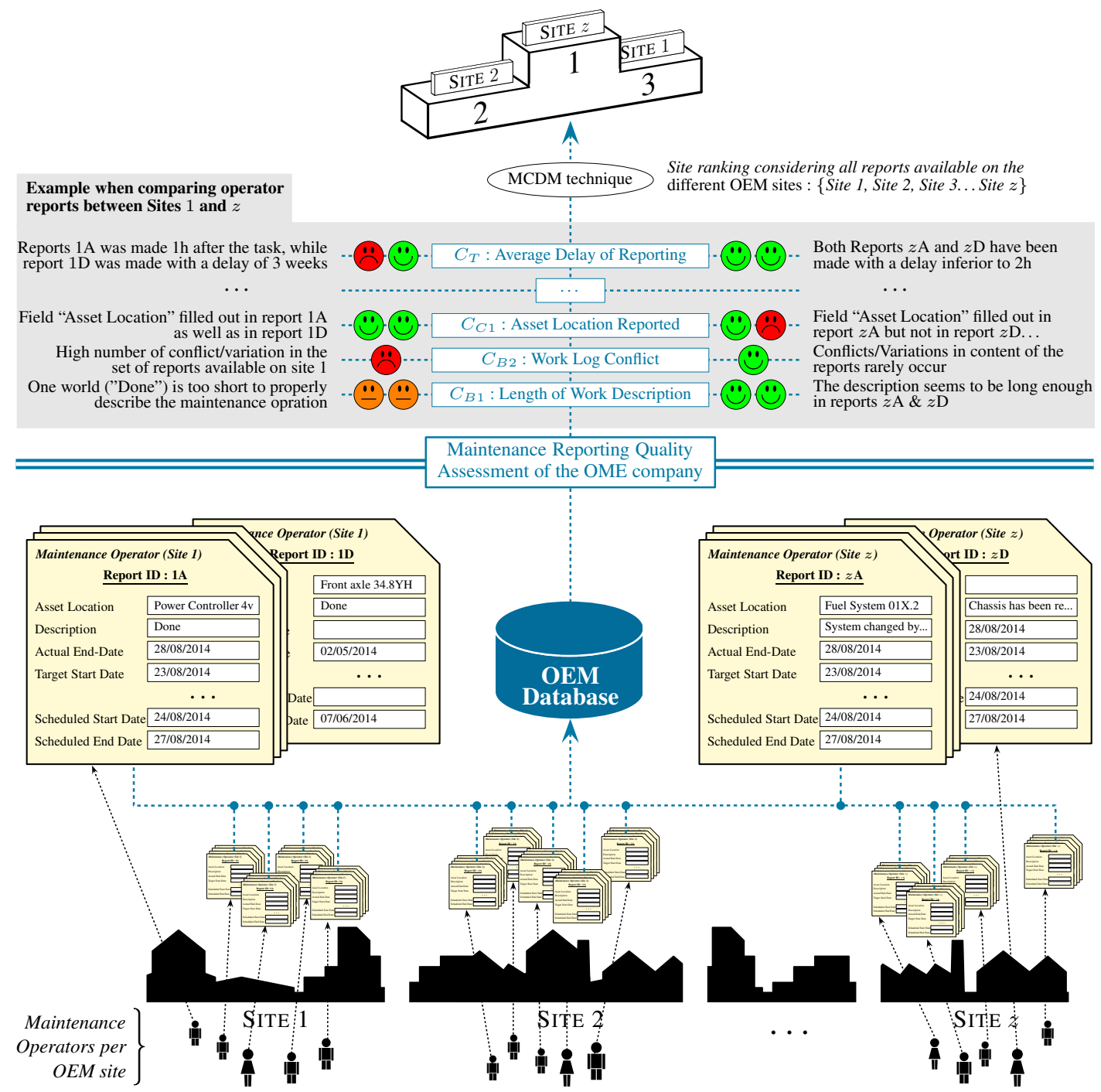

Figure 2: Stages composing the maintenance reporting quality assessment framework

are no better or worse techniques but some techniques are better suited to particular decision-making problems than others. For example, AHP only deals with linear preferences and not with contextual preferences where values of one or several criteria may affect the importance or utility of other criteria. In this study, AHP is used (and combined with TOPSIS) for two reasons: $i$ ) we only deal with linear preferences and ii) AHP provides a powerful impartial, logical, and easy-to-use grading system, thus reducing personal biases and allowing for comparing dissimilar alternatives. Those characteristics are probably the main reasons for its success. According to a recent survey on MCDM techniques (Mardani et al., 2015), AHP is the second most used technique (applied in 16\% of the reviewed literature ${ }^{1}$ ) after Hybrid MCDM $(19.89 \%)$.

\footnotetext{
${ }^{1}$ In total, 150 scientific journal papers were reviewed.
}

\section{AHP-based MRQA framework}

The hierarchical structure defined using AHP consists consists of four levels, as depicted in Figure 3, namely:

- Level 1: the overall goal of the study is to rank the different OEM company sites in terms of maintenance reporting quality;

- Levels 2 and 3: the set of data quality dimensions (criteria) and sub-criteria defined in Table 2;

- Level 4 the OEM company sites representing the alternatives.

Given this hierarchy, AHP does perform the following computation steps for identifying the final ranking of the alternatives with respect to the overall goal:

1. Compare each element in the corresponding level and calibrate them on the numerical scale. This 


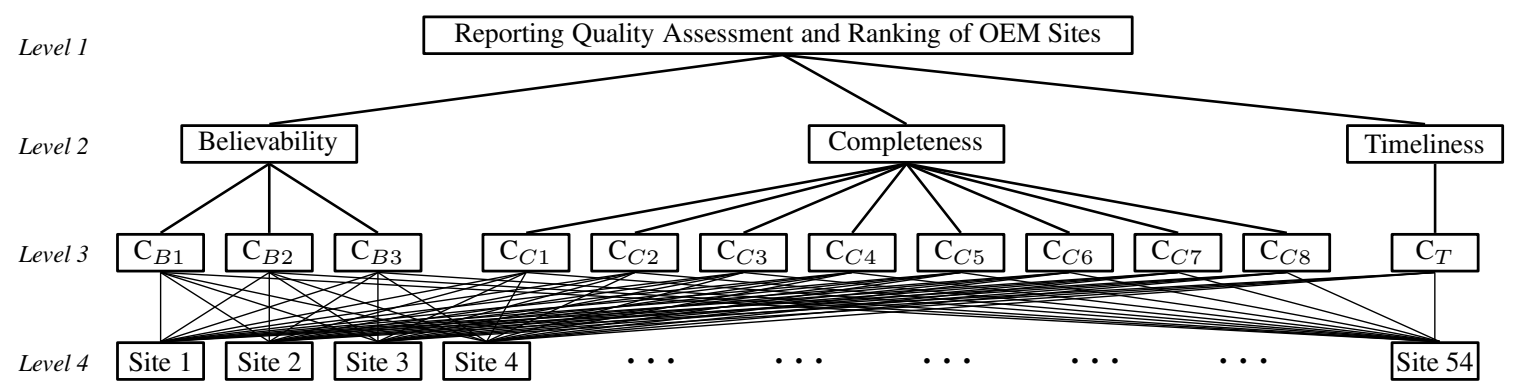

Figure 3: AHP structure of the maintenance reporting quality assessment process

requires $\frac{n(n-1)}{2}$ pairwise comparisons, where $n$ is the number of elements (diagonal elements being equal to " 1 " and the other elements being the reciprocal of the earlier comparisons);

2. Perform calculation to find the maximum eigenvalue, consistency index $(\mathrm{CI})$, consistency ratio (CR), and normalized values;

3. If the computed eigenvalue, CI and CR are satisfactory, then decision/ranking is done based on the normalized values.

These three stages 1, 2 and 3 are detailed in the following sections. In an effort to facilitate the understanding, a scenario is considered in the following, whose parts are preceded by the symbol " $\leadsto$ ".

\subsection{Pairwise comparison based preference measure- ment}

According to Blumenthal (1977), two types of judgment exist, namely:

i) "Comparative judgment, which is the identification of some relations between two stimuli both present to the observer";

ii) "Absolute judgment, which involves the relations between a single stimuli and some information held in short term memory about some former comparison stimuli, or about some previously experienced measurement scale using which the observer rates the single stimulus."

In a comparative/relative measurement, each alternative is compared with many other alternatives, that is why this is also referred in the AHP literature to as "pairwise comparisons as ratio measurement" (Mumpower et al., 2012). In an absolute measurement, each alternative is compared with an ideal alternative the expert knows of or can imagine, that is why this is referred to as "pairwise comparison based preference measurement". This section details the "pairwise comparison based preference measurement" approach, which is used at level 2 and 3 of the AHP structure ( $c f$. Figure 3 ), while section 4.2 details the "pairwise comparisons as ratios" approach, which is used at level 4.

Regarding pairwise comparison based preference measurement, decision makers have to evaluate the importance of one criterion (or sub-criterion) with respect to the others. To this end, OEM stakeholders perform pairwise comparisons among the identified criteria as formalized in Eq. 1, with $m$ the number of criteria to be compared (e.g., at level 2: $m=\left|\left\{\mathrm{C}_{B}, \mathrm{C}_{C}, \mathrm{C}_{T}\right\}\right|=3$ ). The expert evaluation is carried out based on the 1- to 9-point Saaty's scale: $\{1,3,5,7,9\} ; w_{i j}=1$ meaning that $\mathrm{C}_{i}$ and $\mathrm{C}_{j}$ are of equal importance and $w_{i j}=9$ meaning that $\mathrm{C}_{i}$ is strongly favored over $C_{j}$. Note that all variables used in this paper are summarized in Table 3.

$$
\begin{aligned}
& \begin{array}{lll}
\mathrm{C}_{1} & \ldots & \mathrm{C}_{m}
\end{array} \\
& P=\underset{\mathrm{C}_{m}}{\mathrm{C}_{1}}\left[\begin{array}{ccc}
w_{11} & \ldots & w_{1 m} \\
\vdots & \ddots & \vdots \\
w_{m 1} & \ldots & w_{m m}
\end{array}\right]
\end{aligned}
$$

The computation of the normalized eigenvector of $P$ then enables to turn qualitative data into crisp ratios. Although several approaches exist in the literature for normalized eigenvector computation, the Simple Additive Weighting (SAW) method (Hwang \& Yoon, 1981) is used in this study, namely:

$$
\begin{aligned}
W_{C_{i}} & =\frac{\sum_{j=1}^{m} w_{i j}}{\sum_{k=1}^{m} \sum_{j=1}^{m} w_{k j}}, \quad w_{j i}= \begin{cases}1 & i=j \\
\frac{1}{w_{i j}} & i \neq j\end{cases} \\
\mathcal{W}_{C} & =\left[W_{C_{1}}, . ., W_{C_{i}}, . ., W_{C_{m}}\right]
\end{aligned}
$$

$P$ is characterized as consistent if, and only if Eq. 3 is respected. However, it is not that simple to fulfill this prerequisite when dealing with real expert preferences, or when the number of criteria increases. Saaty (1980) proved that for consistent reciprocal matrix, the largest eigenvalue is equal to the size of the comparison matrix (or $\lambda_{\max }=m$ ) and, accordingly, introduced CI as the deviation or degree of consistency ${ }^{2}$

\footnotetext{
${ }^{2} \mathrm{RI}$ corresponds to the consistency index of a pairwise matrix generated randomly.
} 
Table 3: Variable definitions

\begin{tabular}{|c|c|}
\hline Variables & Description \\
\hline $\mathrm{C}_{x}$ & $\begin{array}{l}\text { abbreviation for criterion } x \text { with } x=\{1,2, . ., m\} \text {. Three criteria are defined at level } 2 \text { of the hierarchy structure, namely: } \\
\mathrm{C}_{B}, \mathrm{C}_{C}, \mathrm{C}_{T} \text { (cf. Table } 2 \text { ). }\end{array}$ \\
\hline $\mathrm{C}_{x h}$ & $\begin{array}{l}\text { abbreviation for a sub-criterion of criterion } x \text { with } h=\{1,2, \ldots, y\} \text {. In this study, } h=\{1 . .3\} \text { for } x=B \text { (i.e., three sub-criteria } \\
\left.\text { of } \mathrm{C}_{B}\right), h=\{1 . .8\} \text { for } x=C \text { (i.e., three sub-criteria of } \mathrm{C}_{C} \text { ) and } h=\emptyset \text { for } x=T \text { (i.e., } \mathrm{C}_{T} \text { does not have sub-criteria). }\end{array}$ \\
\hline$P$ & abbreviation for "Pairwise Comparison matrix", whether at level 2, 3 or 4 of the AHP structure. \\
\hline$w_{i j}$ & crisp value of a pairwise comparison matrix located at row $i$, column $j$ of $P$. \\
\hline $\mathrm{A}_{l}$ & $\begin{array}{l}\text { represents an alternative } l \text { in the AHP structure, with } l=\{1,2, \ldots, z\} \text {. In this study, } l \text { is the set of OEM sites to be } \\
\text { assessed/ranked in terms of maintenance reporting quality. }\end{array}$ \\
\hline$W_{C_{x}}, W_{C_{x h}}$ & $\begin{array}{l}\text { represents the eigenvalue of criterion } C_{x} \text { or sub-criterion } C_{x h} \text { (the eigenvector results from the } P \text { 's weight derivation } \\
\text { process). In practice, it indicates the importance of one (sub)criterion over the others. }\end{array}$ \\
\hline$I_{\phi}^{C_{x h}}\left(\mathrm{~A}_{l}\right)$ & $\begin{array}{l}\text { represents a digital indicator used for computing pairwise comparisons as ratios (i.e., measurable elements). Two indica- } \\
\text { tors are defined, namely } \phi=\{\text { fill, avg, var }\} \text { (see Eqs. 10, } 14 \text { and 16). }\end{array}$ \\
\hline$W_{C_{x h}}^{\mathrm{A}_{l}}$ & $\begin{array}{l}\text { represents the eigenvalue of alternative } \mathrm{A}_{l} \text { with respect to sub-criterion } \mathrm{C}_{x h} \text {. In practice, it indicates how good (or bad) } \\
\text { the data quality is, regarding alternative/site } l \text {, with respect to } \mathrm{C}_{x h} .\end{array}$ \\
\hline Rep_Total $\left(\mathrm{A}_{l}\right)$ & function returning the total number of reports available on Site $l$. \\
\hline $\operatorname{Size} \_D e l a y\left(r, \mathrm{~A}_{l}\right)$ & $\begin{array}{l}\text { function returning either (i) the reporting delay value or (ii) description length value of a given report (denoted by } r \text { ) } \\
\text { available on Site } l \text {. }\end{array}$ \\
\hline Rep_filled $\left(\mathrm{A}_{l}\right)$ & function returning the number of reports (on Site $l$ ) for which a given "form field" has been filled out. \\
\hline $\operatorname{Rep} \_\operatorname{var}\left(\mathrm{A}_{l}\right)$ & function returning the number of reports/work orders (on Site $l$ ) containing content variation/conflicts. \\
\hline
\end{tabular}

(see Eq. 4). If CR is smaller or equal to $10 \%$, the inconsistency is regarded as acceptable.

$$
\begin{gathered}
\mathrm{w}_{i j}=\mathrm{w}_{i k} \times \mathrm{w}_{k j} \\
\forall i, k \in \mathbb{N} \mid i \neq k ; j \in \mathbb{N}-\{i, k\} \\
\mathrm{CI}=\frac{\lambda_{\max }-m}{m-1} \quad \mathrm{CR}=\frac{\mathrm{CI}}{\mathrm{RI}}
\end{gathered}
$$

$\Rightarrow$ In this scenario, pairwise comparisons are filled out by the OEM's executive officer. Eq. 5 shows the officer preference specifications regarding criteria at Level 2 of the AHP structure. The computed normalized eigenvector shows that the officer judges all criteria (at this level) of equal importance. Eq. 6 shows the pairwise comparisons carried out at Level 3 of the AHP structure, with regard to sub-criteria $C_{B x} \mid x=$ $\{1,2,3\}$ (see Eq. 7 for the details of $\mathrm{W}_{C_{B 1}}$ computation). The eigenvector ( $c f$. Eq. 6) emphasizes that the officer judges "Length of Work Description" (i.e., $C_{B 1}$ ) slightly more important than "Work Log Conflict" (i.e., $C_{B 2}$ ) for his/her own task, and highly more important than "Technician Log Variation" (i.e., $C_{B 3}$ ).

$$
\begin{aligned}
& \mathrm{C}_{B} \quad \mathrm{C}_{C} \quad \mathrm{C}_{T} \\
& \begin{array}{l}
\mathrm{C}_{B} \\
\mathrm{C}_{C} \\
\mathrm{C}_{T}
\end{array}\left[\begin{array}{lll}
1 & 1 & 1 \\
1 & 1 & 1 \\
1 & 1 & 1
\end{array}\right] \begin{array}{l}
W_{C_{B}} \\
W_{C_{C}} \\
W_{C_{T}}
\end{array}\left[\begin{array}{l}
0.33 \\
0.33 \\
0.33
\end{array}\right] \\
& \mathrm{CR}=0 \\
& \mathrm{C}_{B 1} \quad \mathrm{C}_{B 2} \quad \mathrm{C}_{B 3} \\
& \begin{array}{l}
\mathrm{C}_{B 1}\left[\begin{array}{ccc}
1 & 3 & 5 \\
\mathrm{C}_{B 2} \\
\mathrm{C}_{B 3}
\end{array}\left[\begin{array}{ccc}
\frac{1}{3} & 1 & 3 \\
\frac{1}{5} & \frac{1}{3} & 1
\end{array}\right] \begin{array}{l}
W_{C_{B 1}} \\
W_{C_{B 2}} \\
W_{C_{B 3}}
\end{array}\left[\begin{array}{l}
0.61 \\
0.29 \\
0.10
\end{array}\right]\right. \\
\mathrm{CR}=0.040
\end{array}
\end{aligned}
$$

$$
\begin{aligned}
W_{C_{B 1}} & =\frac{1+3+5}{1+3+5+\frac{1}{3}+1+3+\frac{1}{5}+\frac{1}{3}+1} \\
& =0.61
\end{aligned}
$$

Similarly, the OEM officer carries out pairwise comparisons between sub-criteria $\mathrm{C}_{C x} \mid x=$ $\{1,2, . ., 8\}$, as detailed in Eq. 8. According to the resulting eigenvector, $\mathrm{C}_{C 1}$ is deemed as the most important sub-criterion $\left(W_{C_{C 1}}\right)$, followed by $\mathrm{C}_{C 3}$ and $\mathrm{C}_{C 2}$ respectively. Since $\mathrm{C}_{T}$ does not have any sub-criterion, no pairwise comparison is required.

\subsection{Pairwise comparisons as ratio measurement}

As previously mentioned, pairwise comparisons as ratio measurement is used at level 4 of the AHP structure in order to compare alternatives with respect to each criterion, based upon measurable/supervised system parameters, e.g. how many times the field "DLC Code" $\left(\mathrm{C}_{C 6}\right)$ has been reported on Site $l$ compared with the other sites (i.e., how many times such as form field has been left empty by maintenance operators). Eq. 9 gives insight into the pairwise comparisons as ratio matrix of the set of alternatives/sites $\mathrm{A}_{l}$ with respect to the monitored system parameter $C_{x h}$. The ratio value is denoted by $\mathrm{I}_{\phi}^{C_{x h}}\left(\mathrm{~A}_{l}\right)$, as described in Table 3 . The normalized eigenvector values of the pairwise comparisons as ratio matrix with respect to criterion $C_{x h}$ are denoted by $W_{C_{x h}}^{\mathrm{A}_{l}}$ in Eq. 9. 


\begin{tabular}{|c|c|c|c|c|c|c|c|c|c|c|c|}
\hline & & $\mathrm{C}_{C 1}$ & $\mathrm{C}_{C 2}$ & $\mathrm{C}_{C 3}$ & $\mathrm{C}_{C 4}$ & $\mathrm{C}_{C 5}$ & $\mathrm{C}_{C 6}$ & $\mathrm{C}_{C 7}$ & $\mathrm{C}_{C 8}$ & & \\
\hline & $\mathrm{C}_{C 1}$ & {$[1$} & 3 & 1 & 3 & 7 & 3 & 9 & 3 & $W_{C_{C 1}}$ & {$[0.266$} \\
\hline & $\mathrm{C}_{C 2}$ & $1 / 3$ & 1 & $1 / 3$ & 3 & 5 & 3 & 5 & 3 & $W_{C_{C 2}}$ & 0.167 \\
\hline & $\mathrm{C}_{C 3}$ & 1 & 3 & 1 & 3 & 5 & 3 & 5 & 3 & $W_{C_{C 3}}$ & 0.242 \\
\hline \multirow{5}{*}{$\mathrm{CR}=0.096$} & $\mathrm{C}_{C 4}$ & $1 / 3$ & $1 / 3$ & $1 / 3$ & 1 & 3 & 3 & 5 & 1 & $W_{C_{C 4}}$ & 0.099 \\
\hline & $\mathrm{C}_{C 5}$ & $1 / 7$ & $1 / 5$ & $1 / 5$ & $1 / 3$ & 1 & 1 & 3 & 3 & $W_{C_{C 5}}$ & 0.065 \\
\hline & $\mathrm{C}_{C 6}$ & $1 / 3$ & $1 / 3$ & $1 / 3$ & $1 / 3$ & 1 & 1 & 5 & $1 / 3$ & $W_{C_{C 6}}$ & 0.058 \\
\hline & $\mathrm{C}_{C 7}$ & $1 / 9$ & $1 / 5$ & $1 / 5$ & $1 / 5$ & $1 / 3$ & $1 / 5$ & 1 & $1 / 5$ & $W_{C_{C 7}}$ & 0.023 \\
\hline & $\mathrm{C}_{C 8}$ & $1 / 3$ & $1 / 3$ & $1 / 3$ & 1 & $1 / 3$ & 3 & 5 & 1 & $W_{C_{C 8}}$ & 0.080 \\
\hline
\end{tabular}

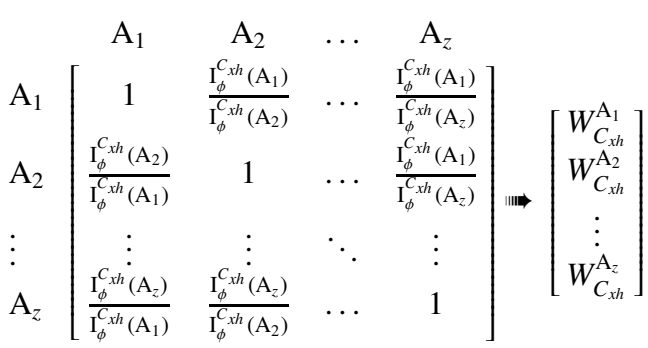

Three digital indicators $\mathrm{I}_{\phi}^{C_{x h}}\left(A_{l}\right)$ are defined (i.e., $\phi=\{$ fill, avg, var $\}$, which are described below. Table 2 highlights what indicators is used with regard to each criterion (see column named "Type"):

- $I_{\text {fil }}^{C_{\text {xh }}}\left(A_{l}\right)($ Filled Indicator - Eq. 10): used to calculate the proportion of reports where a given "field" was filled out on Site $l ; \operatorname{Rep} \_$filled $\left(\mathrm{A}_{l}\right)$ returning the number of reports that have been filled out, and Rep_Total $\left(\mathrm{A}_{l}\right)$ returning the total number of reports available on Site $l$ :

$$
\mathrm{I}_{\text {fill }}^{C_{x h}}\left(\mathrm{~A}_{l}\right)=\frac{\operatorname{Rep} \_ \text {filled }\left(\mathrm{A}_{l}\right)}{\operatorname{Rep} \_\operatorname{Total}\left(\mathrm{A}_{l}\right)}
$$

$\leadsto$ Let us consider pairwise comparisons as ratio measurements between Sites 1 and 2, with respect to $\mathrm{C}_{C 6}$. On Site 1, 76 maintenance reports have been carried out and 45 of them contain the DLC code (meaning that $59 \%$ of the available reports contain the requested information, see Eq. 11), while on Site 2 only $44 \%$ of the available reports contain this information (see Eq. 12). The resulting pairwise comparisons as ratio matrix with respect to $\mathrm{C}_{C 6}$ is given in Eq. 13 , in which the above computed $\mathrm{I}_{\text {fill }}^{\mathrm{C}_{C 6}}\left(A_{1}\right)$ and $\mathrm{I}_{\text {fill }}^{\mathrm{C}_{66}}\left(A_{2}\right)$ are considered for the pairwise comparison as ratio measurement between Sites 1 and 2 (see row 1/column 2 of the matrix, and vice-versa). The resulting eingevector indicates how good (or bad) the reporting quality with respect to $C_{C 6}$ in this case - is regarding each site.

$$
\begin{aligned}
& \mathrm{I}_{\text {fill }}^{\mathrm{C}_{\mathrm{Cb}}}\left(\mathrm{A}_{1}\right)=\frac{45}{76}=59 \% \\
& \mathrm{I}_{\text {fill }}^{\mathrm{C}_{66}}\left(\mathrm{~A}_{2}\right)=\frac{49}{88}=44 \%
\end{aligned}
$$

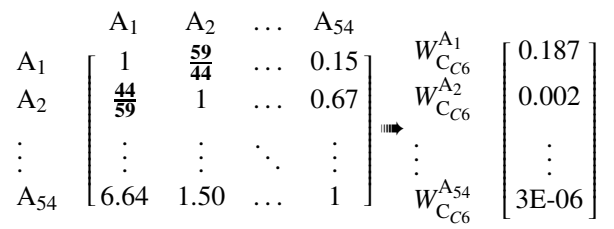

Pairwise comparison as ratios can lead to computational issues when dividing $\frac{\mathrm{I}_{\phi}^{C_{x h}}\left(\mathrm{~A}_{i}\right)}{\mathrm{I}_{\phi}^{C_{\phi h}}\left(\mathrm{~A}_{j}\right)}$ since the denominator may be null. For example, considering the above scenario, if $\mathrm{I}_{\text {fill }}^{C_{66}}\left(A_{2}\right)=0$ (meaning that the DLC Code was never reported by any operator on Site 2), then $\frac{I_{\text {fill }}^{C_{C 6}\left(\mathrm{~A}_{1}\right)}}{\mathrm{I}_{\mathrm{fill}}^{C}\left(\mathrm{~A}_{2}\right)}=\frac{59}{0}$, which prevents from performing the division. To bypass this problem, a penalty score $\theta$ is assigned to the corresponding site (i.e., $\mathrm{A}_{j}$ ) with respect to criterion $C_{x h}$, i.e. $W_{C_{x h}}^{\mathrm{A}_{j}}=\theta$. However, a more indepth study must be conducted to identify what penalty score should be assigned, how it affects the overall results, and so on. This study is presented in Appendix B to avoid overloading the paper.

- $I_{\text {avg }}^{C_{\text {xh }}(i)}$ (Average Indicator - Eq. 14): used to calculate the average delays for maintenance reporting per site (i.e., regarding $\mathrm{C}_{T}$ ), or the average length of work description (i.e., $\mathrm{C}_{B 1}$ ) per site. Mathematically, $I_{\text {avg }}^{C_{x h}}\left(A_{l}\right)$ is computed based on Eq. 14, where $\operatorname{Size} D \operatorname{Delay}\left(k, \mathrm{~A}_{l}\right)$ is either (i) the reporting delay value or (ii) the description length value, of a given report (denoted by $r$ ) available on Site $l$.

$$
\mathrm{I}_{\text {avg }}^{C_{\text {vh }}}\left(\mathrm{A}_{l}\right)=\frac{\sum_{r=1}^{\text {Rep_Total }\left(\mathrm{A}_{l}\right)} \operatorname{SizeDelay}\left(r, \mathrm{~A}_{l}\right)}{\operatorname{Rep} \_\operatorname{Total}\left(\mathrm{A}_{l}\right)}
$$




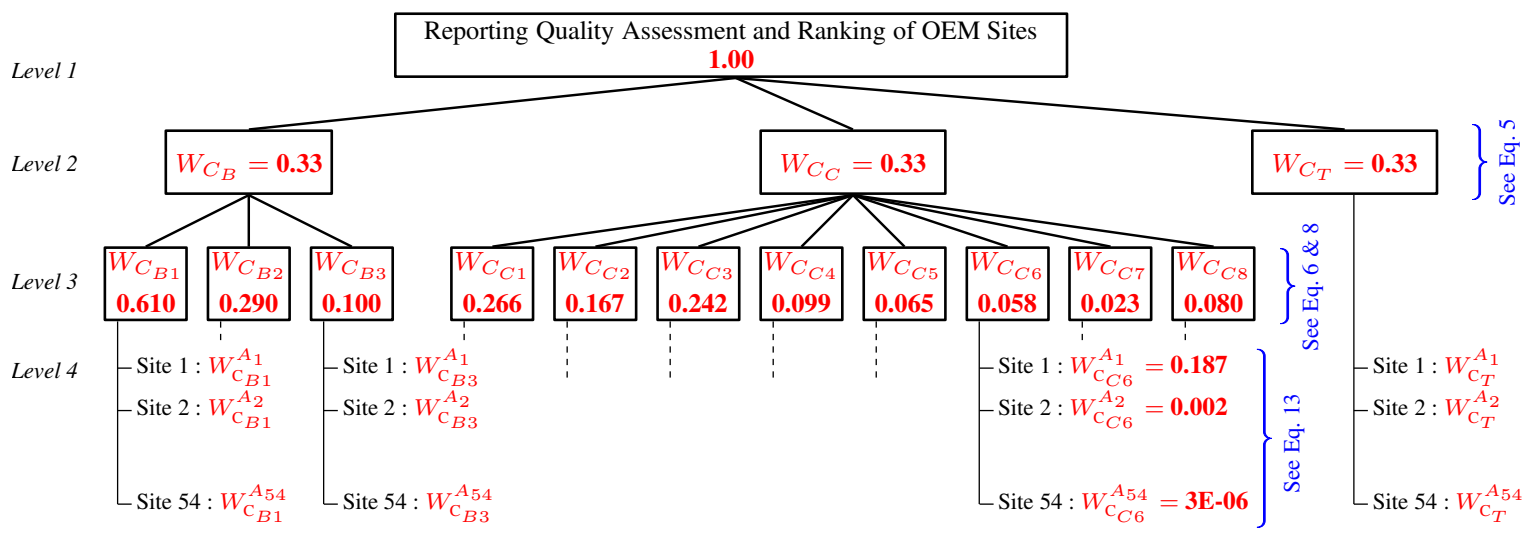

Figure 4: AHP structure and associated weights

$\Rightarrow$ Let us assume that 4 reports are available on Site 1 (i.e. Rep_Total $\left(\mathrm{A}_{1}\right)=4$ ) and that the work description length is respectively equal to 44,5 , 13 and 101. The average indicator with regard to $C_{B 1}$ (on Site 1 ) is therefore equal to 40.75 , as detailed in Eq. 15. The resulting pairwise comparisons as ratios matrix is not presented due to similarities with the matrix detailed in Eq. 13.

$$
\mathrm{I}_{\mathrm{avg}}^{\mathrm{C}_{B 1}}\left(\mathrm{~A}_{l}\right)=\frac{44+5+13+101}{4}=40.75
$$

- $I_{\text {var }}^{C_{x h}}(i)$ (Variation Indicator-Eq. 14): used to calculate the number of reports and/or work orders that contain variations or conflicts. One possible conflict could be that the operator indicates a DLC code related to the car's wheel (see $\mathrm{C}_{C 6}$ ), while indicating in the Work Description (see $\left.\mathrm{C}_{C 2}\right)$ that the car's pump has been fixed. $\mathrm{I}_{\mathrm{var}}^{C_{x h}}\left(\mathrm{~A}_{l}\right)$ is computed based on Eq. 16, with Rep_var $\left(\mathrm{A}_{l}\right)$ the number of reports that contain content variation (or conflicts) on Site $l$.

$$
\mathrm{I}_{\mathrm{var}}^{C_{x h}}\left(\mathrm{~A}_{l}\right)=\frac{\text { Rep_var }\left(\mathrm{A}_{l}\right)}{\text { Rep_Total }\left(\mathrm{A}_{l}\right)}
$$

In an effort to summarize all the variables and weights computed in this section, we provide an "at a glance" representation of the AHP hierarchy in Figure 4, which refers to the different equations considered to compute the variable weights. In the next section, we present how those different weights are aggregated to obtain the final site ranking.

\subsection{Alternative ranking using TOPSIS}

The different weights must now be aggregated in order to obtain a global weight of each alternative with respect to all criteria, which is computed based on Eq. 17. All these global weights are summarized in the form of a matrix in Eq. 18.

$$
G W_{\mathrm{C}_{x h}}^{\mathrm{A}_{l}}=W_{\mathrm{C}_{x h}}^{\mathrm{A}_{l}} \times W_{\mathrm{C}_{x h}} \times W_{\mathrm{C}_{x}}
$$

$$
\begin{aligned}
& \begin{array}{llllllll}
\mathrm{C}_{B 1} & \ldots & \mathrm{C}_{B 3} & \mathrm{C}_{C 1} & \ldots & \mathrm{C}_{C 8} & \mathrm{C}_{T}
\end{array} \\
& \begin{array}{l}
\mathrm{A}_{1} \\
\mathrm{~A}_{2}
\end{array} \quad\left[\begin{array}{cccccccc}
G W_{\mathrm{C}_{B 1}}^{\mathrm{A}_{1}} & \ldots & G W_{\mathrm{C}_{B 3}}^{\mathrm{A}_{1}} & G W_{\mathrm{C}_{C 1}}^{\mathrm{A}_{1}} & \ldots & G W_{\mathrm{C}_{C 8}}^{\mathrm{A}_{1}} & G W_{\mathrm{C}_{T}}^{\mathrm{A}_{1}} \\
\vdots & W_{\mathrm{C}_{B 1}}^{\mathrm{A}_{2}} & \ldots & G W_{\mathrm{C}_{B 3}}^{\mathrm{A}_{2}} & G W_{\mathrm{C}_{C 1}}^{\mathrm{A}_{2}} & \ldots & G W_{\mathrm{C}_{C 8}}^{\mathrm{A}_{2}} & G W_{\mathrm{C}_{T}}^{\mathrm{A}_{2}} \\
\vdots & \ddots & \vdots & \vdots & \ddots & \vdots & \vdots \\
\mathrm{A}_{z} & W_{\mathrm{C}_{B 1}}^{\mathrm{A}_{2}} & \ldots & G W_{\mathrm{C}_{B 3}}^{\mathrm{A}_{z}} & G W_{\mathrm{C}_{C 1}}^{\mathrm{A}_{z}} & \ldots & G W_{\mathrm{C}_{C 8}}^{\mathrm{A}_{z}} & G W_{\mathrm{C}_{T}}^{\mathrm{A}_{z}}
\end{array}\right]
\end{aligned}
$$

$\Rightarrow$ For illustration purposes, Eq. 19 details the global weight computation for $A_{1}$ (i.e., Site 1) with respect to criterion $\mathrm{C}_{C 6}$, which implies to takes into account $W_{\mathrm{C}_{C}}$-related weight.

$$
\begin{aligned}
G W_{\mathrm{C}_{C 6}}^{\mathrm{A}_{1}} & =W_{\mathrm{C}_{C 6}}^{\mathrm{A}_{1}} \times W_{\mathrm{C}_{C 6}} \times W_{\mathrm{C}_{C}} \\
& =0.187 \times 0.058 \times 0.333=0.0036
\end{aligned}
$$

The global weights ( $c f$. Eq. 17) must now be aggregated for each alternative in order to obtain the final quality score, based on which the final site ranking is generated. To this end, the TOPSIS method is employed or, to be more accurate, combined with AHP. TOPSIS introduces for each alternative the closeness coefficient denoted by $R\left(\mathrm{~A}_{l}\right)$, which implies computing for each criterion $x h$ the positive ideal solution (PIS) denoted by $d_{x h}^{+}$and negative ideal solution (NIS) denoted by $d_{x h}^{-}$, as formalized in Eq. 20 and 21 respectively. The distances measuring the separation from PIS and NIS are then computed in Eq. 22 and 23, respectively denoted $D_{\mathrm{A}_{l}}^{+}$and $D_{\mathrm{A}_{l}}^{-}$).

$$
\begin{aligned}
d_{x h}^{+} & =\max _{l=1 . . z}\left(G W_{\mathrm{C}_{x h}}^{\mathrm{A}_{l}}\right) \\
d_{x h}^{-} & =\min _{l=1 . . z}\left(G W_{\mathrm{C}_{x h}}^{\mathrm{A}_{l}}\right) \\
D^{+}\left(\mathrm{A}_{l}\right) & =\sqrt{\sum_{x h}\left(G W_{\mathrm{C}_{x h}}^{\mathrm{A}_{l}}-d_{x h}^{+}\right)^{2}} \quad l=1, . ., z \\
D^{-}\left(\mathrm{A}_{l}\right) & =\sqrt{\sum_{x h}\left(G W_{\mathrm{C}_{x h}}^{\mathrm{A}_{l}}-d_{x h}^{-}\right)^{2}} \quad l=1, . ., z
\end{aligned}
$$

A prior alternative has a longer distance to NIS and a shorter distance to PIS. Consequently, the closeness 


\begin{tabular}{|c|c|c|c|c|}
\hline & $\mid \begin{array}{l}\text { One ranki } \\
\text { Relipyobility }\end{array}$ & g per quality & dimension & |Overall Ranking \\
\hline$\overline{\text { Site } 1}$ & $30^{\text {th }}$ & $3^{\text {rd }}$ & $2^{\text {nd }}$ & $12^{\text {th }}$ \\
\hline Site 2 & $4^{\text {th }}$ & $15^{\text {th }}$ & $27^{\text {th }}$ & $15^{\text {th }}$ \\
\hline Site 11 & $34^{r d}$ & $7^{\text {th }}$ & $\mathbf{1}^{s t}$ & $14^{\text {th }}$ \\
\hline Site 32 & $1^{\text {nd }}$ & $2^{\text {th }}$ & $18^{t h}$ & $7^{\text {th }}$ \\
\hline Site 47 & $19^{\text {th }}$ & $3^{\text {th }}$ & $31^{\text {th }}$ & $28^{t h}$ \\
\hline
\end{tabular}

coefficient to the ideal solution for each alternative can be formulated as in Eq. 24, where $R\left(\mathrm{~A}_{l}\right)$ denotes the final performance score of Site $l$. The larger the $R\left(\mathrm{~A}_{l}\right)$ score, the better the maintenance reporting quality on the corresponding site.

$$
R\left(\mathrm{~A}_{l}\right)=\frac{D^{-}\left(\mathrm{A}_{l}\right)}{D^{+}\left(\mathrm{A}_{l}\right)+D^{-}\left(\mathrm{A}_{l}\right)} \quad l=1, . ., z
$$

The overall site ranking can therefore be generated based on the $R\left(\mathrm{~A}_{l}\right)$ performance scores. Nonetheless, let us note that in Eq. 22 and 23, if:

- $x h=\left\{C_{B 1}, . ., C_{B 3}, C_{C 1}, . ., C_{C 8}, C_{T}\right\}$ : a single and overall ranking of the sites is generated (i.e., all criteria/sub-criteria are aggregated), as shown in Table 4 (see column "Overall Ranking”);

- $x h=\left\{C_{B 1}, . ., C_{B 3}\right\}$ or $x h=\left\{C_{C 1}, . ., C_{C 8}\right\}$ or $x h=\left\{C_{T}\right\}$ : one ranking per quality dimension (i.e., $C_{C}, C_{B}$ or $C_{T}$ ) is generated, as shown in Table 4 (see column named "One ranking per quality dimension"). Having indicators per dimension enable e.g. a site manager to further investigate $i$ ) what dimension(s) must be enhanced in the short, medium or long term, ii) to track the evolution over time of the reporting quality of one or a group of sites with respect to specific dimensions, etc.

$\Rightarrow$ Figure 5 gives insight into how a company's stakeholder can use the "ranking per quality dimension" to better understand how a site behaves (i.e., how good/bad it is) with respect to one or more dimensions ${ }^{3}$ : the larger the surface areas in Figure 5, the better the site ranking and, as a consequence, the better the reporting quality on this site.

\section{OEM use case}

Two distinct use cases, defined at the tactical and operational levels, are presented in this section and show how the Finnish OEM company takes advantage of the MRQA dashboard. Figure 6 provides an

${ }^{3}$ The four sites highlighted in bold in Table 4 are considered and displayed in this example.

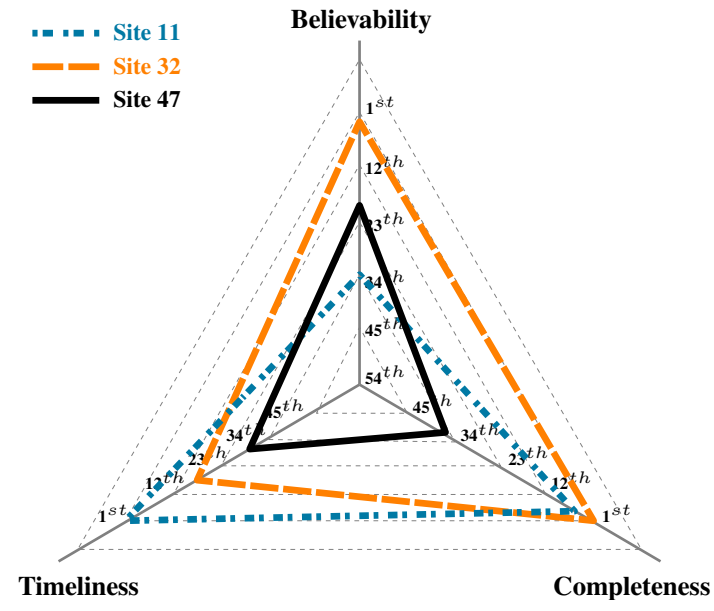

Figure 5: Comparison of sites 11, 32 and 47 ( $c f$. Table 4)

overview of the architecture and associated tools that have been developed/set up in the company: maintainers on the different sites report maintenance work order-related information using the company's online form (see "Reporting Service" in Figure 6). A screenshot of the company's online form is provided in Figure 7(a), which has been annotated to help the reader to understand what form fields correspond to what AHP (sub-)criteria. In total, by summing all reports from all sites, 275585 reports have been processed and analyzed.

The MRQA dashboard thereby enables any site stakeholder (e.g., plant manager, head officer...) to assess - at a given point in time and based on the his/her own preferences - the quality of reporting of the 54 branch offices. As highlighted in Figure 6, when a stakeholder requests for the site ranking service, the overall ranking is computed at the head office (i.e., in Finland). In practice, a set of SQL queries is performed against the different database systems spread over the 54 sites - that contain the maintenance reports. The retrieved information is then used as inputs of the pairwise comparisons as ratio measurement process. A screenshot of the MRQA dashboard is given in Figure 7(b), which provides the stakeholder with the possibility to:

- access it through a web browser;

- vizualize in a user-friendly way both the locations of the OEM sites (see the dashboard element named "Map of Company Sites") and their corresponding quality/ranking (see "Final Assessment \& Ranking”);

- deeper investigate the maintenance reporting quality of one or more sites with respect to one or more quality dimensions (see the "Disintegrated Quality View" dashboard element); 


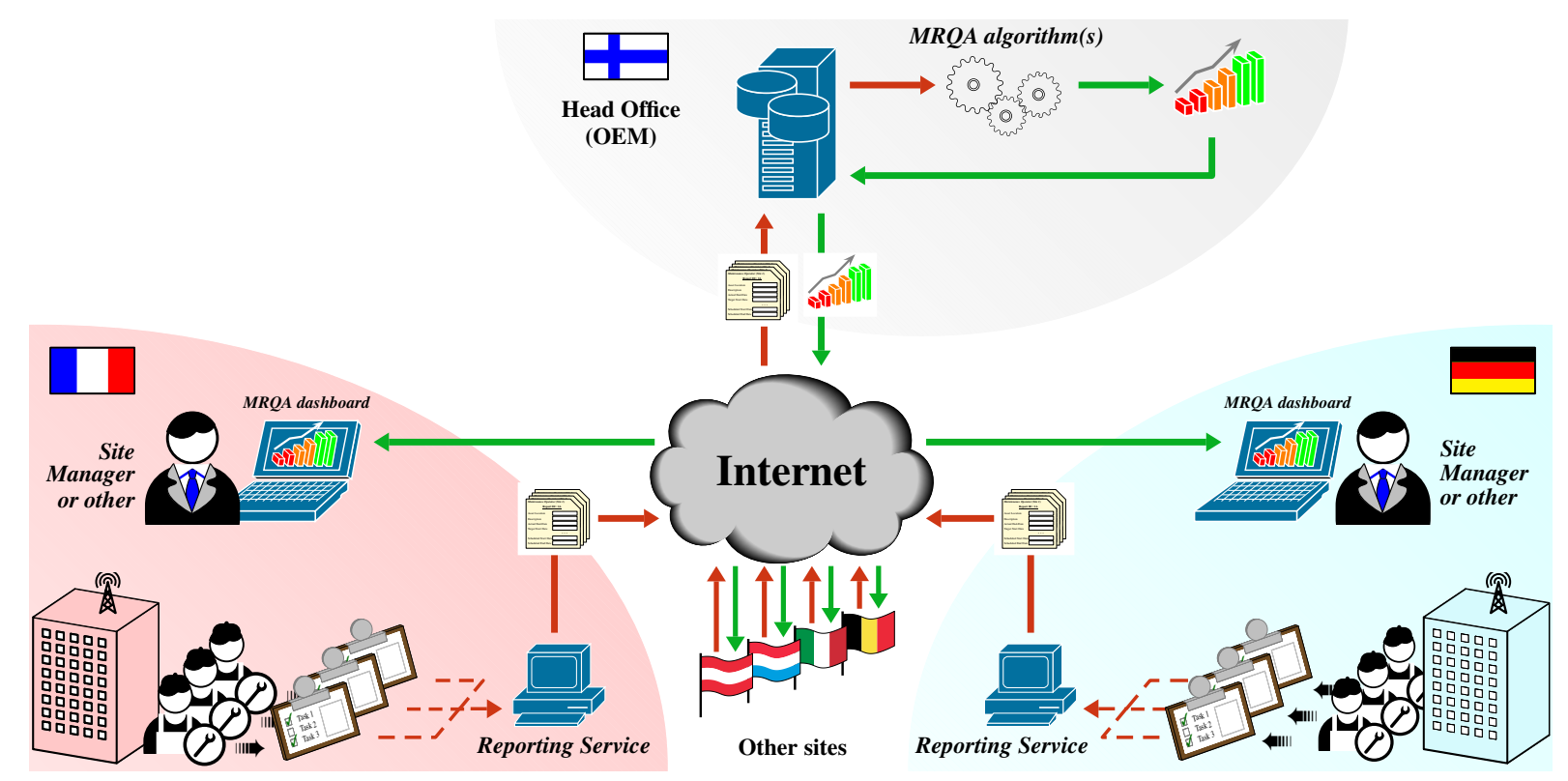

Figure 6: Overall infrastructure underlying the MRQA dashboard

- adjust the assessment period, e.g., to assess/compare sites over the last few weeks, months or years (see the "Assessment period" dashboard element);

- modify his/her preferences related to the criteria importance, e.g. if he/she wants to give - at a specific point in time - further importance to one or more dimensions (e.g., Completeness over Believability) or sub-dimensions (e.g., $\mathrm{C}_{C 4}$ over $\mathrm{C}_{C 1}$ ). This is discussed further in this section, but the reader can already refers to Figure 10 to have an overview of the dashboard functionality.

Two distinct scenarios are presented in sections 5.1 and 5.2 respectively. The first one provides insight into the reporting quality assessment results when considering the importance between criteria as roughly equivalent, while the second scenario highlights how the MRQA dashboard can be used for a specific purpose, namely to set up a cost-reduction action plan in the proposed scenario.

\subsection{Scenario 1: Equivalence between criteria}

At the operational level, the head officer wants to have an overview of the maintenance reporting quality regarding all sites, without prioritizing any quality dimension. To this end, the officer does perform pairwise comparisons by specifying that all criteria are equal in importance (as carried out in Eq. 5), and similarly for the sub-criteria. Figure 8(a) gives insight - in the form of a histogram - into the quality assessment results, where the $x$-axis refers to the 54 sites and the $y$-axis to the quality score obtained after applying
AHP. It can be observed that three sites stand out (having the highest quality scores), namely sites 46,12 and 18 respectively.

The officer wants to further investigate the reasons behind the low quality score of Sites 6 and 54 (i.e., sites having the poorest quality). To this end, the officer selects - in the "Disintegrated Quality View" dashboard element in Figure 7 - these two sites, thus having a deeper insight into the site level quality with respect to each level 2 quality dimension. It can be observed that Site 6 has a particularly poor ranking regarding both the "Timeliness" and "Completeness" dimensions, while Site 54 has a poor ranking regarding "Timeliness" and "Believability". The officer can even go a step further in the analysis in order to understand the reasons behind the low quality score of a site regarding one of these dimensions. For example, in the dashboard's screenshot ( $c f$. "Disintegrated quality view (level 3)" in Figure 7), the officer has selected the 'Completeness' dimension and can visualize the percentage of form fields (which have been turned into sub-criteria $C_{C 1}$ to $C_{C 8}$ ) that have been or not reported with respect to the total number of reports on the selected sites (i.e., on Sites 6 and 54). It can be observed that maintainer operators on Site 6 report less often information than on Site 54, which is the main reason why Site 6 has a lower quality rank than Site 54, as pointed out above. Nonetheless, an interesting point in this graph is that $C_{C 6}$ reports more $C_{C 6}$-related information (i.e., the 'DLC Code'), namely $55 \%$ against $18 \%$ for Site 54 .

In summary, this first scenario offered an overview of the different MRQA dashboard functionalities, and how the associated views can be used as decision 


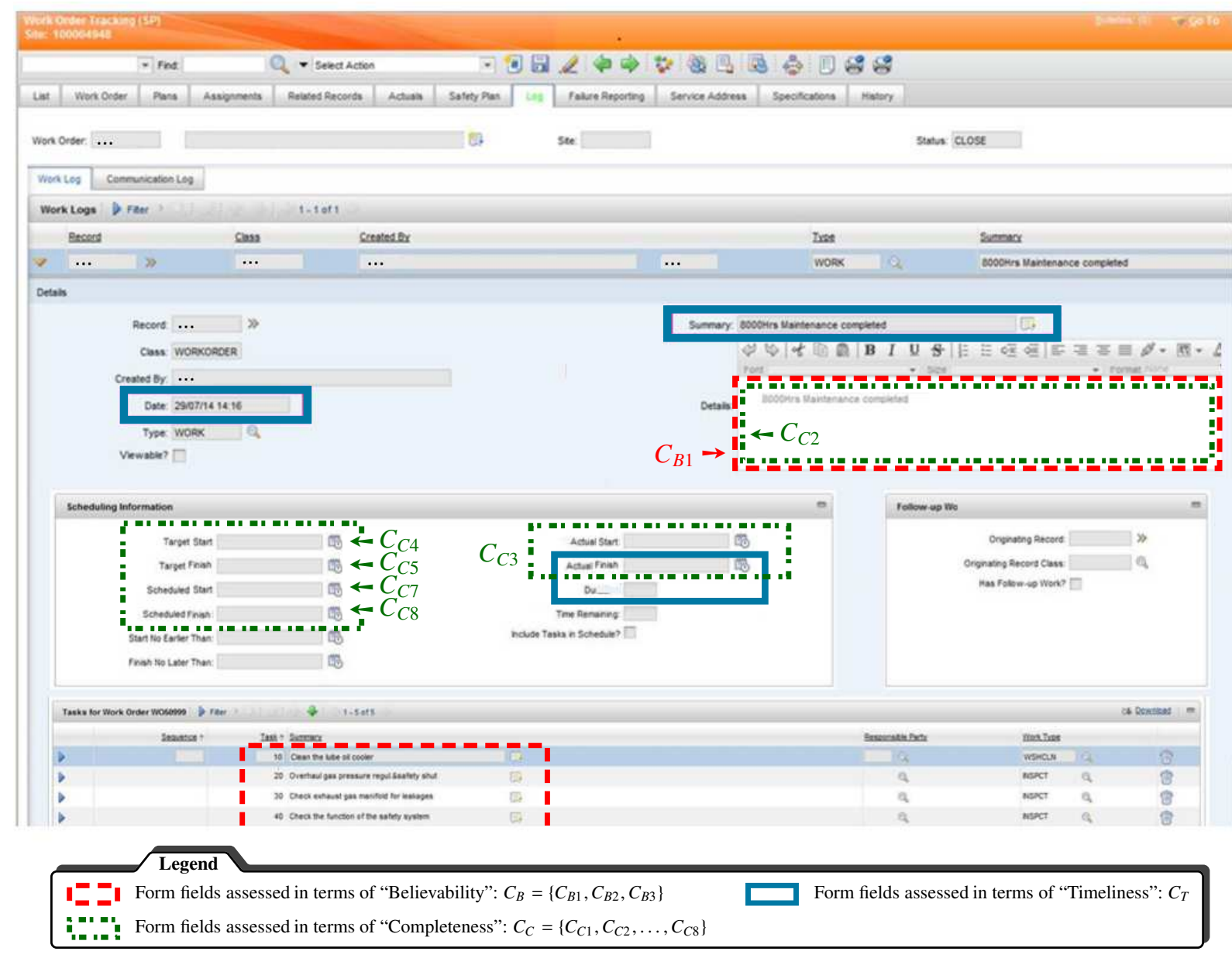

(a) Online form used/filled out by maintainer operators on each OEM site

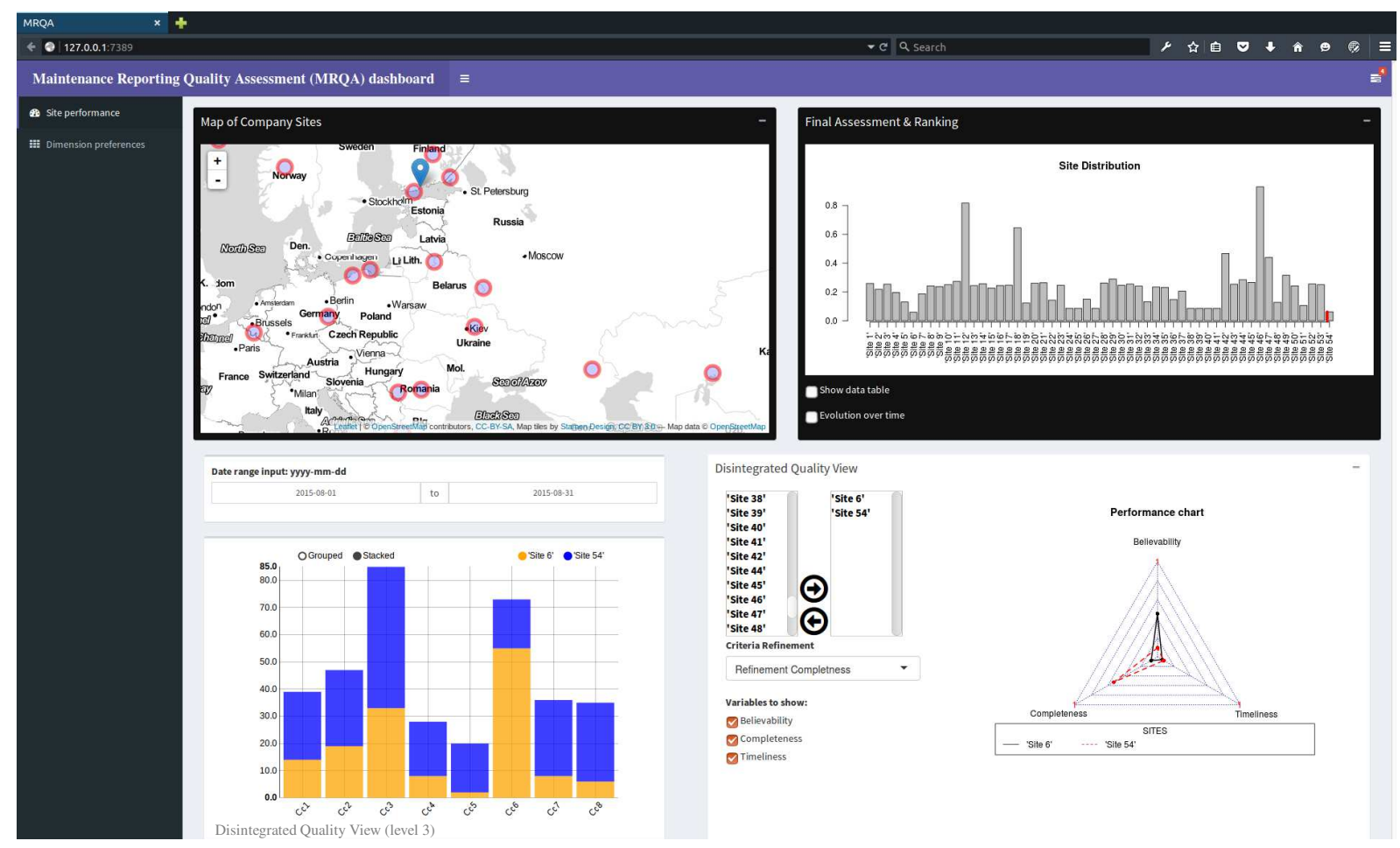

(b) MRQA dashboard interface

Figure 7: Screenshots of the "Maintenance Work Order System" \& the "MRQA dashboard" 


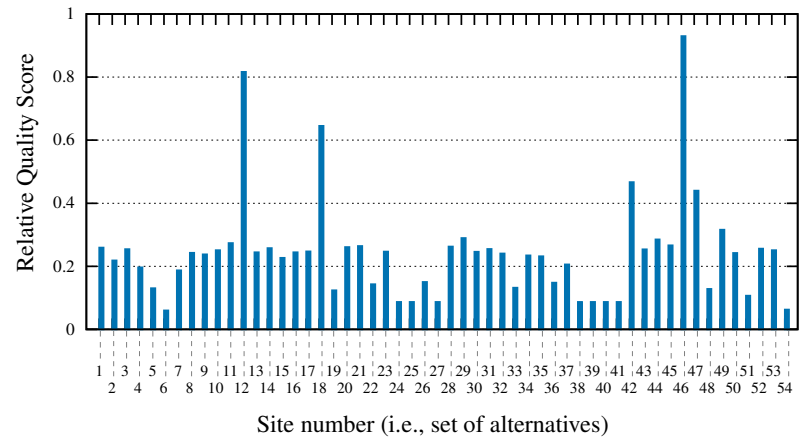

(a) Scenario 1: equivalence between criteria

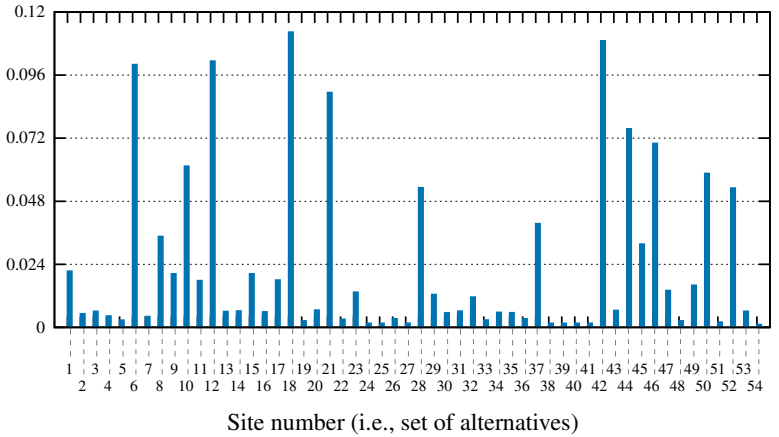

(b) Scenario 2: Cost-reduction action plan

Figure 8: Overall site ranking: Scenarios $1 \& 2$

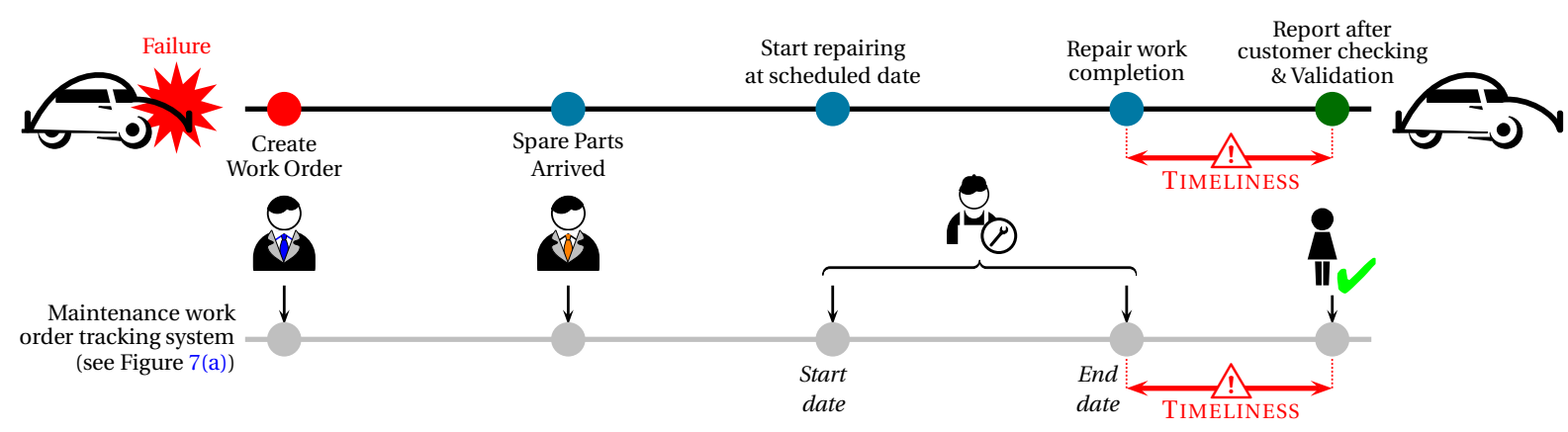

Figure 9: Problem to be addressed in the maintenance reporting process to avoid financial losses

support tools by various maintenance stakeholders. The second scenario, presented in the next section, puts further emphasis on how a site stakeholder can take advantage of the dashboard for improving costreduction action plan.

\subsection{Scenario 2: Cost-reduction action plan}

Over the past few years, the OEM company has been facing a major problem in the maintenance reporting process at the tactical level, leading to substantial financial losses. The traditional maintenance process ${ }^{4}$ is depicted in Figure 9, where a work order is created by the maintenance planner as soon as a problem/failure is reported by the customer. Once the spare parts are supplied on site, the site manager reports it into the system, and the maintainer can start to repair the defective equipment at the scheduled time. As emphasized in Figure 9, the maintainer has to specify - into the maintenance work order tracking system - the "Start date" and "End date" (both dates being taken into account in our AHP under the "Completeness" dimension, and particularly with $C_{C 3}$ ). Following the "Repair work completion" (i.e., End date), it is necessary to wait until the customer checks and validates the maintenance service as depicted in Figure 9. Such a time interval actually corresponds to

\footnotetext{
${ }^{4}$ Only the Scheduled Maintenance Process is described (not the Unscheduled process) to ease the understanding.
}

the "Timeliness" criterion. This interval is very critical for the OEM company because the company has to pay a penalty fee that depends on the time interval (obviously under the condition that the customer does not validate, or complain against the service, and obtains a favorable ruling).

Given the above-mentioned problem, the head officer wants to draw up an assessment of the overall situation (i.e., with regard to each site), and to shape a proper action plan for reducing financial losses. This plan consists first in identifying and managing sites that have the poorest timeliness quality, since they have the highest financial risk. To this end, the officer does specify that Timeliness $\left(C_{T}\right)$ is strongly more important than Believability $\left(C_{B}\right)$ and Completeness $\left(C_{C}\right)$ in order to bring to light the sites with the poorest Timeliness quality. Figure 10 shows how this can be specified through the MRQA dashboard (see red/dashed frame). The final ranking is generated and given in Figure 8(b), showing that Sites 18, 42, 12, 6 and 5 are respectively the branch offices that have the highest risk for monetary losses.

Although the action plan to be set up by the OEM company to reduce such risks on the identified sites is out of scope of this paper, it is worth noting that IoT messaging protocols will likely be implemented in the future to address part of the problem. At a more concrete level, such protocols will be used to generate 'event-based' notifications to the customer as soon 


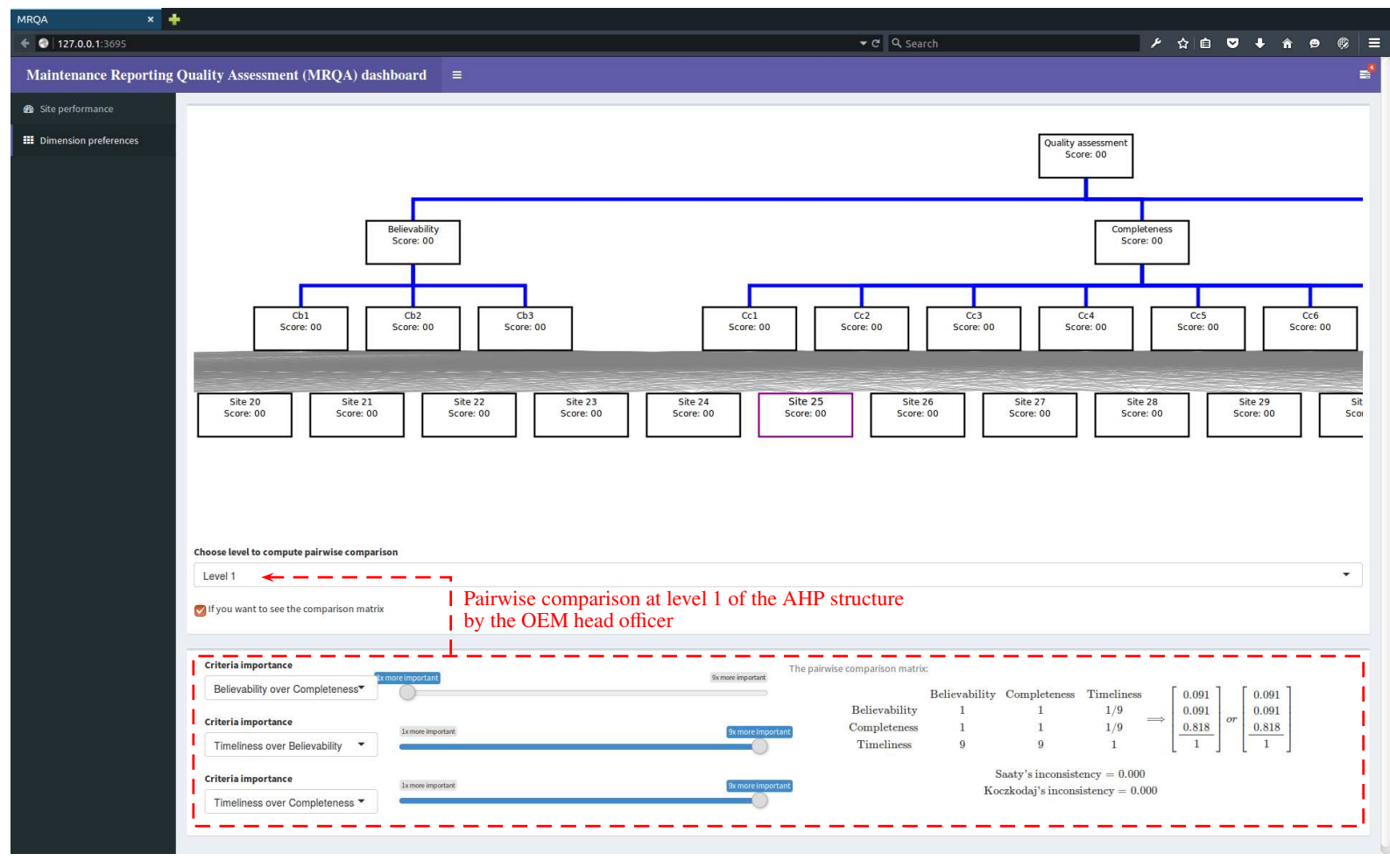

Figure 10: Dashboard/User Interface to adjust the pairwise comparison based preference measurement

as the repair work is completed (i.e., when the "End date" is entered in the system), e.g. by explicitly stating that the customer has a $n$-day deadline to check and validate the maintenance work. From a practical viewpoint, the recent IoT standards published by The Open Group (Främling et al., 2014) will first be implemented on the riskiest sites.

\section{Conclusions, implications, limitations and fu- ture research}

\subsection{Conclusions}

Data, information and knowledge are the "new oil" of the digital era, and are at the heart of all business operations. It is therefore crucial for companies to implement the right infrastructure to monitor and improve the quality of data generated throughout the lifecycle of the company's assets (either physical or virtual assets). It is a fact that the data quality has a significant impact on the overall incomes and expenditures of companies: poor data quality impacting the downstream processes, and reciprocally, high data quality fostering enhanced business activities and decision making. However, it remains challenging to assess information quality, as information is not as tangible as physical assets.

The literature review carried out in this paper brings to light the fact that current expert maintenance systems fail, or have no specific interest, to take into account data quality dimensions in the maintenance re- porting quality assessment process. To fulfill this gap, this paper develops a Maintenance Reporting Quality Assessment (MRQA) dashboard that enables any company stakeholder to easily - and in real-time assess/rank company branch offices in terms of maintenance reporting quality. In this respect, AHP is used to integrate various data quality dimensions as well as expert preferences. The paper presents two scenarios showing how the MRQA dashboard is being used by a Finnish multinational equipment manufacturer to assess and enhance maintenance reporting practices in one or more branch offices. This should contribute to enhance other organization activities such as:

- after-sales services: the quality of maintenance reports makes it possible to assess the maintenance work, thus helping to reach a higher quality after-sales services;

- on the design of future generations of products: processing and analyzing relevant maintenance reports help to better understand how company assets behave throughout their lifecycle which, in turn, help to enhance the design of future generations of products (Främling et al., 2013);

- predictive maintenance strategies: providing real-time and remote predictive maintenance is becoming a very promising area in the so-called IoT, whose objective is to provide systems with the capability to discover and process real-time 
data and contexts so as to make pro-active decisions (e.g., to self-adapt the system before a possible failure) (Främling et al., 2014). Although real-time data is of the utmost importance in the predictive maintenance process, combining such data with historical maintenance reporting data (regarding a specific product item) has the potential to generate new knowledge and lead to more effective and product-centric decisions;

- government regulation compliance: in some domains, it is mandatory to comply with government regulations (e.g., in automotive, avionics, or healthcare domains). In this respect, assessing the quality of maintenance reporting can prevent the company from having regulation noncompliance issues, e.g. by carefully following the data quality on each branch office and identifying as soon as possible quality issues regarding one or more dimensions;

\subsection{Implications}

This research presents three main theoretical implications. First, it contributes to the literature on maintenance management (MM) by proposing a thorough state-of-the-art on the use of MCDM techniques at each MM level (Strategic, Tactical, Operational), which helps identifying criteria at each of these levels (cf. Table 5). This list of criteria can be of potential value to future researchers working in MM. Second, this research contains an approach to identify relevant data quality dimensions (based on existing data quality frameworks), and to turn them into a hierarchical AHP structure. A theoretical framework is then proposed, enabling the assessment and ranking of different company branch offices in terms of maintenance reporting quality. To the best of our knowledge, and as evidenced through our state-of-the-art, this is the first research work that addresses this specific goal.

Finally, the research also contributes three main managerial implications. First, it enables organization stakeholders to realize how important it is to monitor and assess maintenance reporting practices, as it can impact downstream but also upstream activities of the organization. Second, the proposed dashboard helps practitioners to quickly identify, based on their needs and preferences, how one or a group of sites behave (i.e., how good/bad they are) with respect to one or more dimensions. This is helpful to establish their strategic plans to improve current practices, which may result in savings of both money and time.

\subsection{Limitations}

The theoretical implications discussed above rely both on the Krogstie's data quality framework to identify key data quality dimensions, and AHP as MCDM technique to structure these quality dimensions in the form of a hierarchy that makes easier for maintenance stakeholders to specify their needs. However, this research has several limitations. First, only a few concepts and relationships from the Krogstie's framework were considered (see red/bold elements in Figure 1), which is due to the data that has been made available by the Finnish OEM company, as well as to their own expectations/needs. In future research work, the proposed AHP framework and underlying criteria should be extended to take into consideration the other concepts/relationships such as Language Quality (e.g., for domain appropriateness, participant knowledge appropriateness...), Syntactic Quality, etc.. Such an extension might potentially require to combine AHP with other tools and techniques for semantic processing and matching purposes for example, or still for handling uncertainty and vagueness in the expert judgments/preferences (e.g., using fuzzy logic).

Furthermore, although it is already a great achievement for the Finnish company to be able to identify how good/bad their branch offices are in reporting maintenance data, we would have liked to carry out a post-analysis to evaluate benefits of the postaction plans carried out in the different branch offices. For example, we are aware that the company have developed on-site training programs, which have been customized according to the quality results related to each site (e.g., if a site fails in addressing one or more data quality dimensions, the training program is customized accordingly). However, such a postanalysis and insightful implications cannot be provided because of contractual obligations and project constraints.

\subsection{Future research}

From a research perspective, we developed a framework that makes possible the ranking of maintenance sites based on their respective reporting quality. Currently, the proposed MRQA dashboard is limited to the visualization of the site's data quality score and associated rank. In future research work, we would like to extend this tool, and particularly to re-use the final site's (AHP) data quality score as an input parameter of a more advanced framework (e.g., that would integrate live sensor data from manufacture equipment) that would make it possible to decide - in real-time - what predictive failure model for machine is better suited. This is based on two working assumptions:

- a weak assumption: the higher the maintenance reporting quality score on-site (denoted by $R\left(\mathrm{~A}_{l}\right)$ in this study), the higher the confidence of the failure prediction;

- a strong assumption: the confidence of one or more predictive models (e.g., binary logic model, cox regression model, regression trees model...) 
Table 5: Percentage of Criteria used in the Maintenance Management (MM) literature

\begin{tabular}{llllll}
\multicolumn{1}{c}{ Strategic Level } & \multicolumn{2}{c}{ Tactical Level } & & \multicolumn{1}{c}{ Operational Level } \\
\hline Cost & 22.7 & Cost & 21.9 & Cost \\
Resource Availability \& Utilization & 10.1 & Environment./Operation. Condition & 14.1 & Resource Availability \& Utilization & \multicolumn{1}{c}{19.4} \\
Added Value & 7.6 & Safety & 9.4 & Added Value \\
Safety & 7.6 & Resource Availability \& Utilization & 9.4 & DownTime \& Time to repair \\
Reliability & 7.6 & Risk/Severity & 9.4 & Quality \\
Environment./Operation. Condition & 5.0 & DownTime \& Time to repair & 7.8 & Risk/Severity \\
Quality & 5.0 & Reliability & 6.3 & Organizational Process \\
Risk/Severity & 5.0 & Added Value & 3.1 & Failure Frequency \\
Failure Frequency & 4.2 & Knowledge & 3.1 & Knowledge \\
Feasibility (implementation) & 4.2 & Resources Age & 3.1 & Environment./Operation. Condition \\
Repairability & 3.4 & Failure Frequency & 1.6 & Reliability \\
DownTime \& Time to repair & 3.4 & Detectability & 1.6 & Safety \\
Flexibility & 3.4 & Feasibility (implementation) & 1.6 & Repairability \\
Knowledge & 1.7 & Maintenance Frequency & 1.6 & Abilities \& development \\
Geographical Location & 2.5 & Comfort & 1.6 & Collaboration with Stakeholders \\
Component Failed & 1.7 & Automation & 1.6 & Operational Time \\
Detectability & 0.8 & Laws and Regulation & 1.6 \\
Difficulty and Challenges & 0.8 & Number of affected people & 1.6 & Maintenance Impact \\
Support and Services & 0.8 & & Performance \\
Management \& Organization & 0.8 & & Customer Category \\
& & & Number of sorties flown & 1.6 \\
\hline
\end{tabular}

might evolve according to the reporting quality score, whose evolution might even (potentially) differ from one model to another. To put it another way, we might assume that according to the on-site maintenance reporting quality score (e.g., if $R\left(\mathrm{~A}_{l}\right)<60 \%$ ), a binary logic model might provide more confident predictions than a regression trees model, or vice-versa.

The objective of future research will be to validate (or invalidate) these two working assumptions and, if validated, to propose a more advanced framework that is able to switch between two or more predictive models and react accordingly.

\section{Acknowlegement}

The research leading to this publication is supported by the Finnish Metals and Engineering Competence Cluster (FIMECC) S4Fleet program and the National Research Fund Luxembourg (grant 9095399).

\section{Appendix A. Percentage of criteria considered in the Maintenance literature}

Based on the summary matrix given in Table 1, reporting what MCDM techniques is commonly used at each MM level, we carried out an in-depth analysis to identify the most commonly used criteria at each of these level in order to see whether data quality is properly addressed in the maintenance literature, and particularly regarding maintenance reporting activities. The analysis outcome, regarding each MM level, is given in the form of tabular in Table 5, which highlight that data quality is hardly considered in the reviewed papers knowing that "Quality" refers, in most of the reviewed papers, to other quality aspects than Data Quality, except in (Van \& Pintelon, 2014).

\section{Appendix B. Penalty score selection}

The methodology defined to tune the penalty score consists in studying whether the introduced penalty has a significant impact on the overall ranking. Let us consider, in Eq. B.1, the pairwise comparisons as ratio matrix introduced as example in section 4.2, where it is assumed now that the form field(s) related to criterion $\mathrm{C}_{C 6}$ has/have been left empty in all reports carried out on Site 1 (i.e., in $100 \%$ of the reports). Consequently, $\mathrm{I}_{\text {fill }}^{\mathrm{C}_{C 6}}\left(\mathrm{~A}_{1}\right)=0$, as highlighted in the first column and row of the matrix in Eq. B.1. Our strategy is to give out a penalty score (denoted by $\theta$ ) as eigenvalue to the corresponding site (i.e., to Site 1) as shown in Eq. B.1.

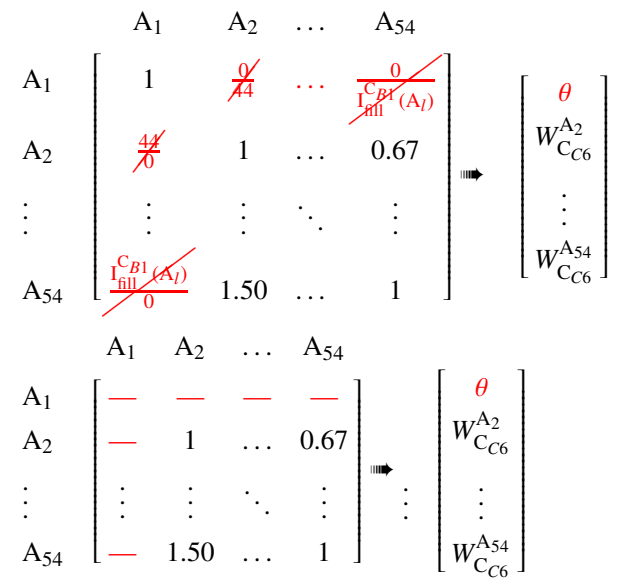

In order to select the penalty score $\theta$, we propose to carry out an analysis to determine whether the introduced score impacts substantially or not on the overall 


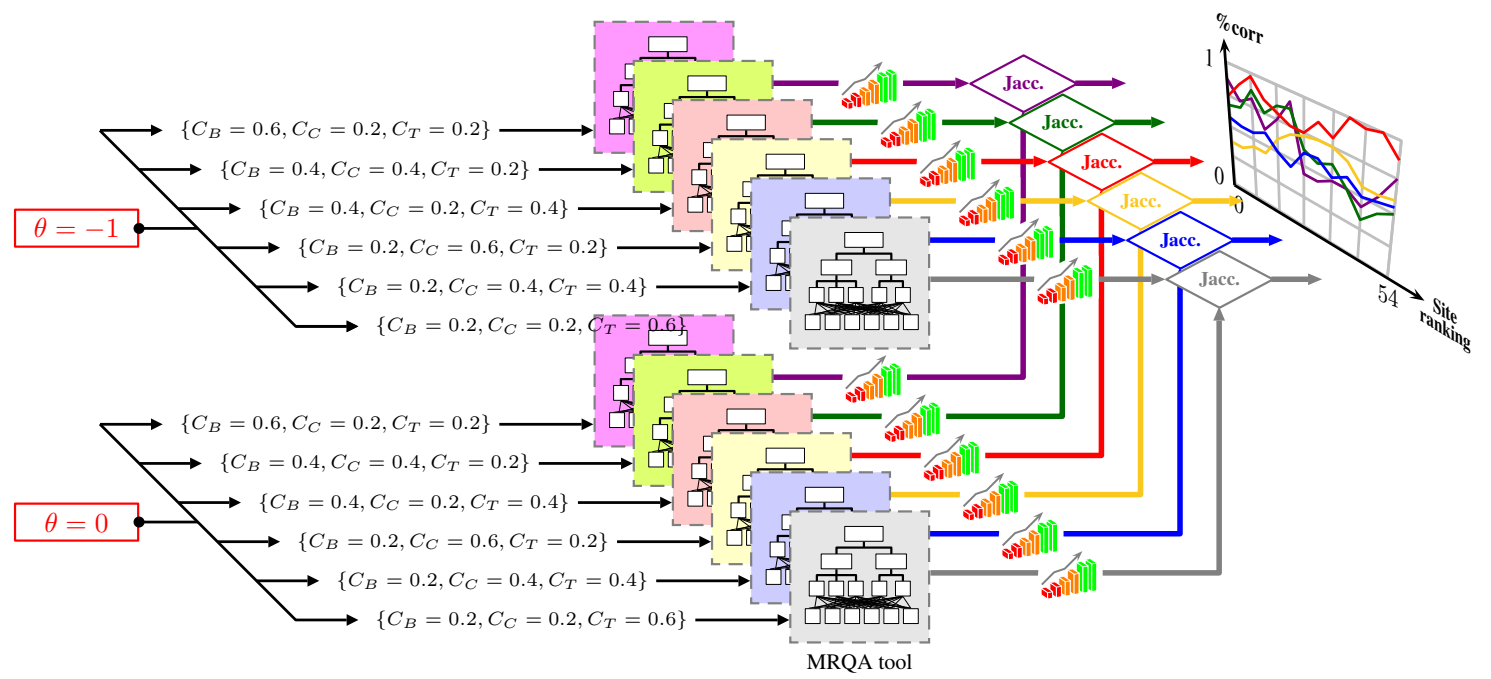

Figure A.11: Comparison process - based on the Jaccard similarity coefficients - set up for similarity measurements between distinct site rankings (i.e., considering various criteria preferences and penalty scores)

ranking. To this end, two distinct penalty scores are considered:

- $\theta=0$ : the site is penalized compared with the other sites since any site that does not get a penalty has automatically an eignevalue greater than zero, or to be more precise $0<W_{C_{x h}}^{\mathrm{A}_{l}}<1$;

- $\theta=-p \mid p \in \mathbb{R}^{-}$: the site is penalized compared to the other sites, whose effect (unlike $\theta=0$ ) is to bring down the overall ranking when aggregating all AHP dimensions/criteria.

To identify whether the penalty scores impact (in a substantial manner) the overall ranking, we propose - as depicted in Figure A.11 - to generate/compute the alternative ranking for each penalty score (considering a given set of criteria weights/preferences) and to compare whether the two rankings vary from each other. This process has been tested for six combinations of criteria weights, as emphasized in Figure A.11. The similarity measure between distinct rankings is based on the Jaccard similarity coefficients, whose principle is described in section Appendix B.1. Results and concluding remarks about the penalty score selection are presented in section Appendix B.2.

\section{Appendix B.1. Jaccard-based similarity measure}

The Jaccard similarity coefficients (Tan et al., 2006) can be used to measure a similarity between two distinct lists $A$ and $B$, as formalized in Eq. B.2 (i.e., the size of the list intersection divided by the size of the list union). In our study, the union size is equal to the number of alternatives/sites $z$. A Jaccard similarity coefficient goes from 0 (no common list) to 1 (identical lists).

$$
J(A, B)=\frac{|A \cap B|}{|A \cup B|}=\frac{|A \cap B|}{z}
$$

Let $A, B$ and $C$ be three distinct lists consisting of five sites $\left\{\mathrm{S}_{1}, . ., \mathrm{S}_{5}\right\}$, where each site receives a final rank as presented in Figure B.12. In this example, two Jaccard similarity coefficients $J(A, B)$ and $J(A, C)$ are calculated. Both coefficients are equal because the intersections $|A \cap B|$ and $|A \cap C|$ have the same cardinality.

\begin{tabular}{|l|c|c|c|}
\cline { 2 - 4 } \multicolumn{1}{c|}{} & $A$ & $B$ & $C$ \\
\hline S1 & 1 & 1 & 7 \\
S2 & 2 & 2 & 6 \\
S3 & 3 & 3 & 1 \\
S4 & 4 & 6 & 2 \\
S5 & 5 & 7 & 3 \\
\hline
\end{tabular}

$$
\begin{aligned}
& J(A, B)=\frac{|A \cap B|}{z}=\frac{|1,2,3|}{|1,2,3,4,5|}=\frac{3}{5} \\
& J(A, C)=\frac{|A \cap C|}{z}=\frac{|1,2,3|}{|1,2,3,4,5|}=\frac{3}{5}
\end{aligned}
$$

Figure B.12: Computation of Jaccard similarity coefficients

In our study, sites are ordered according to their data quality score. It could be worthwhile to define a similarity coefficient that would take into account the rank. To this end, let us define $L_{q}$ to be a sublist of $L$, where $L_{q}$ consists of sites from rank 1 to $q$ $(q \leq z)$. A progressive similarity coefficient $J_{q}(A, B)$ can therefore be computed as in Eq. B.3.

$$
J_{q}(A, B)=J\left(A_{q}, B_{q}\right)
$$

Figure B.13 details the evolution of the Jaccard progressive coefficients $J_{q}(A, B)$ and $J_{q}(A, C)$ with $q=$ $1,2, \ldots, 5$ (see lists $A, B$, and $C$ given in Figure B.12).

\section{Appendix B.2. Penalty score impact and selection}

As previously stated and summarized in Figure A.11, the alternative ranking for each penalty 
$\begin{array}{ll}J_{1}(A, B)=\frac{\left|A_{1} \cap B_{1}\right|}{1}=1.00 & J_{1}(A, C)=\frac{\left|A_{1} \cap C_{1}\right|}{1}=0.00 \\ J_{2}(A, B)=\frac{\left|A_{2} \cap B_{2}\right|}{2}=1.00 & J_{2}(A, C)=\frac{\left|A_{2} \cap C_{2}\right|}{2}=0.00 \\ J_{3}(A, B)=\frac{\left|A_{3} \cap B_{3}\right|}{3}=1.00 & J_{3}(A, C)=\frac{\left|A_{3} \cap C_{3}\right|}{3}=0.33 \\ J_{4}(A, B)=\frac{\left|A_{4} \cap B_{4}\right|}{4}=0.75 & J_{4}(A, C)=\frac{\left|A_{4} \cap C_{4}\right|}{4}=0.50 \\ J_{5}(A, B)=\frac{\left|A_{5} \cap B_{5}\right|}{5}=0.60 & J_{5}(A, C)=\frac{\left|A_{5} \cap C_{5}\right|}{5}=0.60\end{array}$

Figure B.13: Computation of Jaccard progressive coefficients

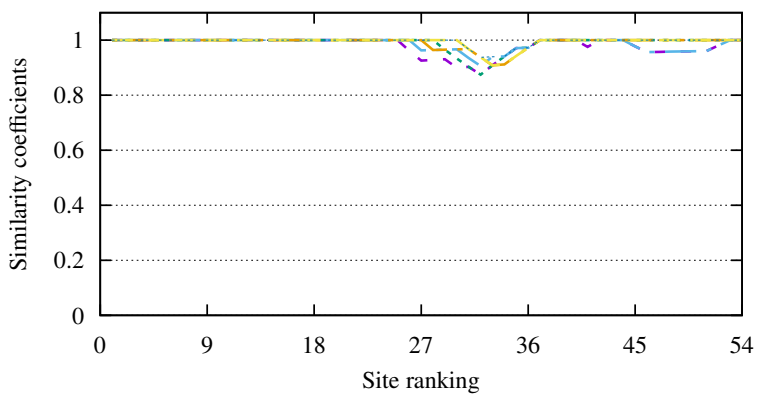

Criteria Preferences: $\left\{C_{B}=0.6, C_{C}=0.2, C_{T}=0.2\right\} \quad--$

Criteria Preferences: $\left\{C_{B}=0.4, C_{C}=0.4, C_{T}=0.2\right\} \quad \ldots \ldots$

Criteria Preferences: $\left\{C_{B}=0.4, C_{C}=0.2, C_{T}=0.4\right\}-$ - -

Criteria Preferences: $\left\{C_{B}=0.2, C_{C}=0.6, C_{T}=0.2\right\} \cdots-\cdots$

Criteria Preferences: $\left\{C_{B}=0.2, C_{C}=0.4, C_{T}=0.4\right\}$

Criteria Preferences: $\left\{C_{B}=0.2, C_{C}=0.2, C_{T}=0.6\right\}$

Figure B.14: Penalty score impact on site ranking: $\theta=0$ vs. $\theta=-1$

score (i.e., for $\theta=0$ and $\theta=-1$ ) is generated, where the two resulting rankings are compared based on the Jaccard similarity measure. In total, six similarity comparisons are performed ( $c f$. Figure A.11), whose results are displayed in Figure B.14. These results show that the choice of the penalty score does not lead to significant changes in the final ranking (although a few sites move up or down between the $27^{\text {th }}$ and $36^{\text {th }}$ positions), and is not dependent on the criteria weights. Given this observation, the penalty score $\theta=0$ has been chosen in this study. An additional reason for choosing this score is that the sum of the eigenvector values are equal to 1 (thus respecting the eigenvector property/axiom), which is not true when choosing $\theta=-1$.

\section{References}

Ahmadi, A., Gupta, S., Karim, R. and Kumar, U. (2010). Selection of maintenance strategy for aircraft systems using multi-criteria decision making methodologies. International Journal of Reliability, Quality and Safety Engineering, 17, 223-243.

Alarcón, M. J., Grau, J. B. and Torres, J. (2007). Application of ELECTRE I method to restoration actions in telecommunication network maintenance. IEEE.

Almeida, A.T. (2012). Multicriteria model for selection of preventive maintenance intervals. Quality and Reliability Engineering International, 28, 585-593.

Almeida-Filho, A., Ferreira, R.J. and Almeida, A. (2013). A DSS based on multiple criteria decision making for maintenance planning in an electrical power distributor. Springer.
Arputhamary, B. and Arockiam, L. (2015). Data Integration in Big Data Environment. Bonfring International Journal of Data Mining, 5, 1.

Azadeh, A., Sheikhalishahi, M., Firoozi, M. and Khalili, S.M. (2013). An integrated multi-criteria Taguchi computer simulation-DEA approach for optimum maintenance policy and planning by incorporating learning effects. International Journal of Production Research, 51, 5374-5385.

Azadeh, A., Sheikhalishahi, M., Khalili, S. M. and Firoozi, M. (2014). An integrated fuzzy simulation-fuzzy data envelopment analysis approach for optimum maintenance planning. International Journal of Computer Integrated Manufacturing, 27,181199.

Azizi, A. and Fathi, K. (2014). Selection of optimum maintenance strategies based on a fuzzy analytic hierarchy process. Management Science Letters, 4, 893-898.

Babashamsi, P., Golzadfar, A., Yusoff, N. I. M., Ceylan, H. and Nor, N. G. M. (2016). Integrated fuzzy analytic hierarchy process and VIKOR method in the prioritization of pavement maintenance activities. nternational Journal of Pavement Research and Technology, 9, 112-120.

Behzadian, M., Khanmohammadi Otaghsara, S., Yazdani, M. and Ignatius, J. (2012). A state-of the-art survey of TOPSIS applications. Expert Systems with Applications, 39, 13051-13069.

Bertolini, M., Bevilacqua, M., Braglia, M. and Frosolini, M. (2004). An analytical method for maintenance outsourcing service selection. International Journal of Quality $\mathcal{E}$ Reliability Management, 21, 772-788.

Bertolini, M. and Bevilacqua, M. (2006). A combined goal programming - AHP approach to maintenance selection problem. Reliability Engineering $\mathcal{E}$ System Safety, 91, 839-848.

Bevilacqua, M. and Braglia, M. (2000). The analytic hierarchy process applied to maintenance strategy selection. Reliability Engineering $\mathcal{G}$ System Safety, 70, 71-83.

Blumenthal, A. L. (1977). The process of cognition. Prentice Hall/Pearson Education.

Cafiso, S., Di, G. A., Kerali, H. and Odoki, J. (2002). Multicriteria analysis method for pavement maintenance management. Transportation Research Record: Journal of the Transportation Research Board, 1816, 73-84.

Cavalcante, C. A. V. and Costa, A. P. C. S. (2010).Multicriteria Model of Preventive Maintenance. Brazilian Journal of Operations $\mathcal{E}$ Production Management, 3,71-86.

Cavalcante, C. A. V., and Ferreira, R. J. P. and de Almeida, A. T. (2010). A preventive maintenance decision model based on multicriteria method PROMETHEE II integrated with Bayesian approach. IMA Journal of Management Mathematics, 21, 333348.

Cavalcante, C.A.V. and De Almeida, A.T. (2007). A multi-criteria decision-aiding model using PROMETHEE III for preventive maintenance planning under uncertain conditions. Journal of Quality in Maintenance Engineering, 13, 385-397.

Certa, A., Enea, M. and Lupo, T. (2013). ELECTRE III to dynamically support the decision maker about the periodic replacements configurations for a multi-component system. Decision support systems, 55,126-134.

Charnes, A., Clark, C. T., and Cooper, W. W. and Golany, B. (1984). A developmental study of data envelopment analysis in measuring the efficiency of maintenance units in the US air forces. Annals of Operations Research, 2,95-112.

Chen, M., Mao, S., \& Liu, Y. (2014). Big data: A survey. Mobile Networks and Applications, 19, 171-209.

Chen, L., Weng, M. and Zhang, G. (2005). Utility Optimality Method for Pipeline Integrity Maintenance Costs. Petroleum Engineering Construction, 2,004.

Chou, J. (2009). Web-based CBR system applied to early cost budgeting for pavement maintenance project. Expert Systems with Applications, 36, 2947-2960.

Coulter, E. D., Sessions, J. and Wing, M. G. (2006). Scheduling forest road maintenance using the analytic hierarchy process and heuristics. Silva Fennica, 40, 143. 
de Almeida, A. T. (2001). Multicriteria decision making on maintenance: spares and contracts planning. European Journal of $\mathrm{Op}$ erational Research, 129,235-241.

de Almeida, A. T., Cavalcante, C. A. V., Alencar, M. H., Ferreira, R. J. P., de Almeida-Filho, A. T and Garcez, T. V. (2015). Decision on Maintenance Outsourcing. Springer.

de Almeida, A. T., Cavalcante, C. A. V., Alencar, M. H., Ferreira, R. J. P., de Almeida-Filho, A. T. and Garcez, T. V. (2015) Decisions on Priority Assignment for Maintenance Planning. Springer.

de Almeida, A. T., Cavalcante, C. A. V., Alencar, M. H., Ferreira, R. J. P., and de Almeida-Filho, A. T. and Garcez, T. V. (2015). Preventive Maintenance Decisions. Springer.

de un Caso, E. (2008). The Efficiency of Preventive Maintenance Planning and the Multicriteria Methods: A Case Study. Computación y Sistemas, 12,208-215.

Dehghanian, P., Fotuhi-Firuzabad, M., Bagheri-Shouraki, S. and Kazemi, A. A. R. (2012). Critical component identification in reliability centered asset management of power distribution systems via fuzzy AHP. Systems Journal, 4, 593-602.

dGonçalves, C. D. F. and Dias, J. A. M. and Cruz-Machado, V. A (2014). Decision Methodology for Maintenance KPI Selection: Based on ELECTRE I. Springer.

Duffuaa, S. O., Ben-Daya, M., Al-Sultan, K. S. and Andijani, A A. (2001). A generic conceptual simulation model for maintenance systems. Journal of Quality in Maintenance Engineering, 7, 207-219.

Durán, O. (2011). Computer-aided maintenance management systems selection based on a fuzzy AHP approach. Advances in Engineering Software, 42, 821-829.

e Costa, C. A .B., Carnero, M. C. and Oliveira, M. D. (2012). A multi-criteria model for auditing a Predictive Maintenance Programme. European Journal of Operational Research, 217,381393.

Emovon, I., Norman, R. A. and Murphy, A. J.(2010). Hybrid MCDM based methodology for selecting the optimum maintenance strategy for ship machinery systems. Journal of Intelligent Manufacturing, ,1-13.

Eslami, S., Sajadi, S. M. and Kashan, A. H. (2014). Selecting a preventive maintenance scheduling method by using simulation and multi criteria decision making. International Journal of Logistics Systems and Management, 18, 250-269.

Fallah-Fini, S., Triantis, K., Rahmandad, H. and Jesus, M. (2015). Measuring dynamic efficiency of highway maintenance operations. Omega, 50,18-28.

Fang, C.-C., \& Huang, Y.-S. (2008). A Bayesian decision analysis in determining the optimal policy for pricing, production, and warranty of repairable products. Expert Systems with Applications, 35, 1858-1872.

Farhan, J. and Fwa, T. (2009). Pavement maintenance prioritization using analytic hierarchy process. Transportation Research Record: Journal of the Transportation Research Board, 12-24.

Ferdousmakan, M., Vasili, M., Vasili, M., Tang, S.H. and Lim, N.T (2014). Selection of Appropriate Risk-based Maintenance Strategy by Using Fuzzy Analytical Hierarchy Process. In 4rd European Seminar on Computing, Pilsen, Czech Republic (pp. 77).

Främling, K., Holmström, J., Loukkola, J., Nyman, J., and Kaustell, A. (2013). Sustainable PLM through Intelligent Products. Engineering Applications of Artificial Intelligence, 26, 789-799.

Fouladgar, M.M., Yazdani-Chamzini, A., Lashgari, A., Zavadskas, E. K. and Turskis, Z. (2012). Maintenance strategy selection using AHP and COPRAS under fuzzy environment. International journal of strategic property management, 16, 85-104.

Främling, K., Kubler, S., and Buda, A. (2014). Universal Messaging Standards for the IoT from a Lifecycle Management Perspective. IEEE Internet of Things Journal, 1, 319-327.

García-Cascales, M. S., and Lamata, M. T. (2009). Selection of a cleaning system for engine maintenance based on the analytic hierarchy process. Computers $\mathcal{E}$ Industrial Engineering, $56,1442-1451$.

Garmabaki, A. H. S., Ahmadi, A. and Ahmadi, M. (2016).
Maintenance Optimization Using Multi-attribute Utility Theory. Springer.

Gomez, A. and Carnero, M. C. (2011). Selection of a Computerised Maintenance Management System: a case study in a regional health service. Production Planning and Control, 22,426-436.

Goossens, A. J. M. and Basten, R. J. I. (2015). Exploring maintenance policy selection using the Analytic Hierarchy Process; an application for naval ships. Reliability Engineering $\mathcal{G}$ System Safety, 142, 31-41.

Ha, S. H. and Krishnan, R. (2008). A hybrid approach to supplier selection for the maintenance of a competitive supply chain. Expert Systems with Applications, 34, 1303-1311.

Hankach, P. and Lepert, P. (2011). Multicriteria Decision Analysis for Prioritizing Road Network Maintenance Interventions. International Journal of Pavements, 10,

Hjalmarsson, L. and Odeck, J. (1996). Efficiency of trucks in road construction and maintenance: an evaluation with data envelopment analysis. Computers $\mathcal{E}$ operations research, 23,393-404.

Hosseini Firouz, M. and Ghadimi, N. (2015). Optimal preventive maintenance policy for electric power distribution systems based on the fuzzy AHP methods. Complexity, DOI 10.1002/cplx.21668.

Hwang, C. L., and Yoon, K. (1981). Multiple Attribute DecisionMaking Methods and Applications. Springer Verlag, Berlin, Heidelberg, New York.

Ilangkumaran, M. and Kumanan, S. (2009). Selection of maintenance policy for textile industry using hybrid multi-criteria decision making approach. Journal of Manufacturing Technology Management, 20, 1009-1022.

Ilangkumaran, M. and Kumanan, S. (2012). Application of hybrid VIKOR model in selection of maintenance strategy. International Journal of Information Systems and Supply Chain Management (IJISSCM), 5,59-81.

Jarke, M. and Vassiliou, Y. (1997). Data Warehouse Quality: A Review of the DWQ Project. In Proceedings of the Conference on Information Quality (IQ1997), Cambridge, MA (pp. 299-313).

Jeon, J., Kim, C. and Lee, H. (2011). Measuring efficiency of total productive maintenance (TPM): a three-stage data envelopment analysis (DEA) approach. Total Quality Management $\mathcal{E}$ Business Excellence, 22, 911-924.

Jones-Farmer, L. A., Ezell, J. D. and Hazen, B. T. (2014). Applying control chart methods to enhance data quality. Technometrics, 56, 29-41.

Kahn, B. K., Strong, D. M., and Wang, R. Y. (2002). Information quality benchmarks: product and service performance. Communications of the ACM, 45, 184-192.

Köksal, G., Batmaz, 1., and Testik, M. C. (2011). A review of data mining applications for quality improvement in manufacturing industry. Expert systems with Applications, 38, 13448-13467.

Krogstie, J., Lindland, O. I., and Sindre, G. (1995). Defining quality aspects for conceptual models. In Proceedings of the IFIP8.1 Working Conference on Information Systems Concepts: Towards a Consolidation of Views (ISCO), Marburg, Germany (pp. 216231).

Kumar, G. and Maiti, J. (2012). Modeling risk based maintenance using fuzzy analytic network process. Expert Systems with Applications, 39, 9946-9954.

Kuo, T. C. and Wang, M. L. (2012). The optimisation of maintenance service levels to support the product service system. International Journal of Production Research, 50, 6691-6708.

Labib, A. W., O'Connor, R. F. and Williams, G. B. (1998). An effective maintenance system using the analytic hierarchy process. Integrated Manufacturing Systems, 9, 87-98.

Levrat, E., and Iung, B. and Crespo Marquez, A. (2008). Emaintenance: review and conceptual framework. Production Planning $\mathcal{E}$ Control, 19, 408-429.

Li, C., and Xu, M. and Guo, S. (2007). ELECTRE III based on ranking fuzzy numbers for deterministic and fuzzy maintenance strategy decision problems. IEEE.

Li, J., Tao, F., Cheng, Y. and Zhao, L.. (2015). Big data in product lifecycle management. The International Journal of Advanced 
Manufacturing Technology, 81, 667-684.

Liu, J. and Yu, D. (2004). Evaluation of plant maintenance based on data envelopment analysis. Journal of Quality in Maintenance Engineering, 10,203-209.

Liu, M. and Frangopol, D. M. (2006). Decision support system for bridge network maintenance planning. Springer.

Liu, J., LU, X. and QU, C. (2012). A Priority Sorting Approach of Maintenance Task During Mission Based on ELECTRE TRI. Fire Control \& Command Control, ,S1.

Mardani, A., Jusoh, A. and Zavadskas, E. K. (2015). Fuzzy multiple criteria decision-making techniques and applications - Two decades review from 1994 to 2014. Expert systems with Applications, 42, 4126-4148.

Maurino, A. and Batini, C. (2009). Methodologies for data quality assessment and improvement. ACM Computing Surveys, 41, 152.

Moazami, D., Behbahani, H. and Muniandy, R. (2011). Pavement rehabilitation and maintenance prioritization of urban roads using fuzzy logic. Expert Systems with Applications, 38, 1286912879.

Mobley, R. K. (2002). An introduction to predictive maintenance. Butterworth-Heinemann.

Monte, M. B. S. and others. (2015). A MCDM Model for Preventive Maintenance on Wells for Water Distribution. In IEEE International Conference on QSystems, Man, and Cybernetics (SMC), 2015 (pp.268-272).

Monte, M. B.S and de Almeida-Filho, A. T. (2016). A Multicriteria Approach Using MAUT to Assist the Maintenance of a Water Supply System Located in a Low-Income Community. Water Resources Management, , 1-14.

Muchiri, P., Pintelon, L., Gelders, L. and Martin, H. (2011). Development of maintenance function performance measurement framework and indicators. International Journal of Production Economics, 131, 295-302.

Mumpower, J. L., Phillips, L. D., Renn, O. and Uppuluri, V. R. R. (2012). Expert Judgment and Expert Systems. Springer Science \& Business Media.

Nyström, B. and Söderholm, P. (2010). Selection of maintenance actions using the analytic hierarchy process (AHP): decisionmaking in railway infrastructure. Structure and Infrastructure Engineering, 6, 467-479.

Ofner, M., Otto, B. and Österle, H. (2013). A Maturity Model for Enterprise Data Quality Management. Enterprise Modelling and Information Systems Architectures, 8, 4-24.

Ouma, Y. O., Opudo, J. and Nyambenya, S.(2015). Comparison of Fuzzy AHP and Fuzzy TOPSIS for Road Pavement Maintenance Prioritization: Methodological Exposition and Case Study. Advances in Civil Engineering, ,DOI 10.1155/2015/140189.

Ozbek, M. E., de la Garza, J. M. and Triantis, K. (2010). Data and modeling issues faced during the efficiency measurement of road maintenance using data envelopment analysis. Journal of Infrastructure Systems, 16, 21-30.

Ozbek, M. E., de la Garza, J. M. and Triantis, K. (2010). Efficiency measurement of bridge maintenance using data envelopment analysis. Journal of Infrastructure Systems, 16, 31-39.

Palma, J., de León Hijes, F. C. G., Martínez, M. C. and Cárceles, L. G. (2010). Scheduling of maintenance work: A constraint-based approach. Expert Systems with Applications, 37, 2963-2973.

Peck, M. W., Scheraga, C. A. and Boisjoly, R. P. (1998). Assessing the relative efficiency of aircraft maintenance technologies: an application of data envelopment analysis. Transportation Research Part A: Policy and Practice, 32, 261-269.

Pintelon, L. M. and Gelders, L.F. (1992). Maintenance management decision making. European journal of operational research, 58, 301-317.

Pourjavad, E., Shirouyehzad, H. and Shahin, A. (2013). Selecting maintenance strategy in mining industry by analytic network process and TOPSIS. International Journal of Industrial and Systems Engineering, 15, 171-192.

Pramod, V. R., Sampath, K., Devadasan, S.R., Jagathy Raj, V.P. and Moorthy, G. D. (2007). Multicriteria decision making in main- tenance quality function deployment through the analytical hierarchy process. International Journal of Industrial and Systems Engineering, 2, 454-478.

Roll, Y., Golany, B. and Seroussy, D.(1989). Measuring the efficiency of maintenance units in the Israeli Air Force. European Journal of Operational Research, 43, 136-142.

Rouse, P., Putterill, M. and Ryan, D. (2002). Integrated performance measurement design: insights from an application in aircraft maintenance. Management Accounting Research, 13, 229248.

Saaty, T. L. (1980). The Analytic Hierarchy Process. New York: McGraw-Hill

Sampaio, S. F. M., Dong, C. and Sampaio, P. (2015). DQ 2 S A framework for data quality-aware information management. Expert Systems with Applications, 42, 8304-8326.

Shafiee, M. (2015). Maintenance strategy selection problem: an MCDM overview. Journal of Quality in Maintenance Engineering, 21, 378-402.

Shahin, A., Pourjavad, E. and Shirouyehzad, H. (2012). Selecting optimum maintenance strategy by analytic network process with a case study in the mining industry. International Journal of Productivity and Quality Management, 10, 464-483.

Sheikhalishahi, M. (2014). An integrated simulation-data envelopment analysis approach for maintenance activities planning. International Journal of Computer Integrated Manufacturing, 27, 858-868.

Shyjith, K., Ilangkumaran, M. and Kumanan, S. (2008). Multicriteria decision-making approach to evaluate optimum maintenance strategy in textile industry. Journal of Quality in Maintenance Engineering, 14, 375-386.

Simpson, L. (1996). Do decision makers know what they prefer?: MAVT and ELECTRE II. Journal of the Operational Research Society, 47, 919-929.

Sophie, S.-Z., Thomas, A., Dominik, L., Ralf, H., Pierrick, B. and Javier, G.-S. (2014). Supreme sustainable predictive maintenance for manufacturing equipment. In European Congress $\mathcal{G}$ Expo on Maintenance and Asset Management (EuroMaintenance), Helsinki, Finland, (pp. 1-6).

Sun, S. (2004). Assessing joint maintenance shops in the Taiwanese Army using data envelopment analysis. Journal of Operations Management, 22, 233-245.

Taghipour, S., Banjevic, D. and Jardine, A. K. S. (2011). Prioritization of medical equipment for maintenance decisions. Journal of the Operational Research Society, 62, 1666-1687.

Tan, P.-N., Steinbach, M. and Kumar, V. (2006). Introduction to data mining. Addison-Wesley Longman Publishing Co., Inc.

Tan, Z., Li, J., Wu, Z., Zheng, J. and He, W. (2011). An evaluation of maintenance strategy using risk based inspection. Safety science, 49, 852-860.

Thor, J., Ding, S. and Kamaruddin, S. (2013). Comparison of multi criteria decision making methods from the maintenance alternative selection perspective. The International Journal of Engineering and Science, 2, 27-34.

Triantaphyllou, E., Kovalerchuk, B., Mann, L. and Knapp, G. M. (1997). Determining the most important criteria in maintenance decision making. Journal of Quality in Maintenance Engineering, 3, 16-28.

Trojan, F. and Morais, D. C. (2012). Using ELECTRE TRI to support maintenance of water distribution networks. Pesquisa $\mathrm{Op}$ eracional, 32, 423-442.

Trojan, F. and Morais, D. C. (2012). Prioritising alternatives for maintenance of water distribution networks: a group decision approach. Water $\mathrm{Sa}, 38,555-564$.

Umbrich, J., Neumaier, S. and Polleres, A. (2015). Quality assessment \& evolution of Open Data portals. In 3rd International Conference on Future Internet of Things and Cloud (FiCloud), Roma, Italy (pp. 404-411).

Van den Bergh, J., De Bruecker, P., Beliën, J., De Boeck, L. and Demeulemeester, E. (2013). A three-stage approach for aircraft line maintenance personnel rostering using MIP, discrete event simulation and DEA. Expert Systems with Applications, 40, 2659- 
2668.

Van Horenbeek, A. and Pintelon, L. (2014). Development of a maintenance performance measurement frameworkusing the analytic network process (ANP) for maintenance performance indicator selection. Omega, 42, 33-46.

Vujanović, D., Momčilović, V., Bojović, N. and Papić, V. (2012). Evaluation of vehicle fleet maintenance management indicators by application of DEMATEL and ANP. Expert Systems with Applications, 39, 10552-10563.

Waisberg, D. (September 2015). Data Analytics: A Matrix for Better Decision Making. https://www.thinkwithgoogle. com/articles/data-analysis-a-matrix-for-betterdecision-making.html\#utm_source=LinkedIn\&utm_ medium=social\&utm_campaign=Think

Wakchaure, S. S. and Jha, K. N. (2011). Prioritization of bridges for maintenance planning using data envelopment analysis. Construction Management and Economics, 29, 957-968.

Wang, R. Y., and Strong, D. M. (1996). Beyond accuracy: What data quality means to data consumers. Journal of management information systems, 12, 5-33.

Wang, J., Fan, K. and Wang, W. (2010). Integration of fuzzy AHP and FPP with TOPSIS methodology for aeroengine health assessment. Expert Systems with Applications, 37, 8516-8526.

Wang, L., Chu, J. and Wu, J. (2007). Selection of optimum maintenance strategies based on a fuzzy analytic hierarchy process. International Journal of Production Economics, 107, 151-163.

Wellsandt, S., Wuest, T., Hribernik, K., and Thoben, K.-D. (2015) Information Quality in PLM: A Product Design Perspective. In Advances in Production Management Systems: Innovative Production Management Towards Sustainable Growth (AMPS), Tokyo, Japan (pp. 515-523).

$\mathrm{Xu}, \mathrm{L}$. and $\mathrm{He}, \mathrm{W}$. and $\mathrm{Li}, \mathrm{S}$. (2010). Internet of Things in industries: A survey. IEEE Transactions on Industrial Informatics, 10, 2233-2243.

Zaim, S., Turkyilmaz, A., Acar, M. F., Al-Turki, U. and Demirel, O. F. (2012). Maintenance strategy selection using AHP and ANP algorithms: a case study. Journal of Quality in Maintenance Engineering, 18, 16-29.

Zhangqiong, W. and Guozheng, S. (1999). A Study of Appraisal and Decision-making Support System for Maintenance Scheme of Metal Structure of Crane. Journal of Wuhan University, 5, 007. 